\title{
1 Protective pan-ebolavirus combination therapy by two multifunctional human 2 antibodies
}

4 AUTHORS: Pavlo Gilchuk ${ }^{1, *}$, Charles D. Murin ${ }^{2, *}$, Robert W. Cross ${ }^{3,4, *}$, Philipp A. Ilinykh ${ }^{3,5}$, 5 Kai Huang ${ }^{3,5}$, Natalia Kuzmina ${ }^{3,5}$, Viktoriya Borisevich ${ }^{3,4}$, Krystle N. Agans ${ }^{3,4}$, Joan B.

6 Geisbert $^{3,4}$, Robert H. Carnahan ${ }^{1}$, Rachel S. Nargi ${ }^{1}$, Rachel E Sutton ${ }^{1}$, Naveenchandra

7 Suryadevara ${ }^{1}$, Seth J. Zost ${ }^{1}$, Robin G. Bombardi ${ }^{1}$, Alexander Bukreyev ${ }^{3,4,5}$, Thomas W.

8 Geisbert $^{3,4}$, Andrew B. Ward ${ }^{2}$ and James E. Crowe, Jr. ${ }^{1,6,7 * *}$

\section{Affiliations:}

$11{ }^{1}$ Vanderbilt Vaccine Center, Vanderbilt University Medical Center, Nashville, TN, 37232, USA.

$12{ }^{2}$ Department of Integrative Structural and Computational Biology, The Scripps Research

13 Institute, La Jolla, CA, 92037, USA.

$14{ }^{3}$ Galveston National Laboratory, Galveston, TX, 77550, USA.

$15{ }^{4}$ Department of Microbiology \& Immunology, University of Texas Medical Branch, Galveston, TX, 1677555 , USA.

$17 \quad{ }^{5}$ Department of Pathology, University of Texas Medical Branch, Galveston, TX, 77555, USA.

$18{ }^{6}$ Department of Pathology, Microbiology, and Immunology, Vanderbilt University Medical Center, 19 Nashville, TN, 37232, USA.

$20{ }^{7}$ Department of Pediatrics, Vanderbilt University Medical Center, Nashville, TN, 37232, USA.

Keywords: Ebolavirus; ebolavirus infection; glycoprotein; viral antibodies; neutralizing antibodies; epitope mapping; antibody therapeutics

\section{Contact information:}

James E. Crowe, Jr., M.D. [LEAD CONTACT]

Ann Scott Carell Chair, Departments of Pediatrics, and Pathology, Microbiology and Immunology

Director, Vanderbilt Vaccine Center

Mail: 
Vanderbilt Vaccine Center

11475 Medical Research Building IV

2213 Garland Avenue

Nashville, TN 37232-0417, USA

(615) 343-8064

\section{Additional Title Page Footnotes}

Abstract

Ebolaviruses cause a severe and often fatal illness with the potential for global spread.

44 Monoclonal antibody-based treatments that have become available recently have a narrow 45 therapeutic spectrum and are ineffective against ebolaviruses other than Ebola virus (EBOV), including medically important Bundibugyo (BDBV) and Sudan (SUDV) viruses. Here we report the development of a therapeutic cocktail comprising two broadly neutralizing human antibodies rEBOV-515 and rEBOV-442 that recognize non-overlapping sites on the ebolavirus glycoprotein (GP). Antibodies in the cocktail exhibited synergistic neutralizing activity and resisted viral escape, and they were optimized for their Fc-mediated effector function activities. The cocktail protected non-human primates from ebolavirus disease caused by EBOV, BDBV, or SUDV with high therapeutic effectiveness. High-resolution structures of the cocktail antibodies in complex with GP revealed the molecular determinants for neutralization breadth and potency. This study

54 provides advanced preclinical data to support clinical development of this cocktail for panebolavirus therapy.

\section{Introduction}

The Filoviridae family consists of six antigenically distinct species, including Zaire

60 Bundibugyo ebolavirus (Bundibugyo virus [BDBV]), Taï Forest ebolavirus (Taï Forest virus

61 [TAFV]), Reston ebolavirus (Reston virus [RESV]) (Feldmann et al., 2020; Kuhn et al., 2019),

62 and Bombali ebolavirus (Bombali virus [BOMV])(Goldstein et al., 2019). Three ebolaviruses - 
63 EBOV, BDBV, and SUDV, are responsible for severe disease and occasional deadly outbreaks in Africa posing a significant health threat. A total of 19 confirmed ebolavirus disease (EVD) outbreaks caused by EBOV have occurred, with $>30,000$ people infected to date and an average reported mortality rate of $\sim 70 \%$. In 2021 , there are ongoing EVD outbreaks in the Democratic Republic of the Congo (DRC) and Guinea (WHO, 2021). BDBV has caused two confirmed outbreaks and infected 206 people ( $32 \%$ mortality rate), and SUDV has been responsible for eight confirmed outbreaks and infected 779 people ( 53\% mortality rate) (WHO, 2021). The largest EVD epidemic to date occurred in 2013-2016 in West Africa with a total of 28,610 disease cases and 11,308 deaths reported (WHO, 2021), highlighting the urgent need for development of medical countermeasures. Monoclonal antibody (mAb) therapies have demonstrated safety and significant survival benefit in the treatment of acute EVD caused by EBOV in randomized controlled human trials (Gaudinski et al., 2019; Levine, 2019; Mulangu et al., 2019; Sivapalasingam et al., 2018), and several investigational human mAb treatments have been shown to reverse the advanced EVD in non-human primates caused by EBOV (Bornholdt et al., 2019; Corti et al., 2016; Gilchuk et al., 2020b; Pascal et al., 2018; Qiu et al., 2014), BDBV (Bornholdt et al., 2019; Gilchuk et al., 2018b), or SUDV (Bornholdt et al., 2019; Herbert et al., 2020). By 2020, two mAb-based therapeutics - ansuvimab-zykl (Ebanga) and atoltivimab + maftivimab + odesivimab-ebgn (Inmazeb) - have been developed and approved by the Food and Drug Administration (FDA) for clinical use (FDA, 2020a, b). Both of these approved antibody treatments are monospecific to EBOV, and therefore, not indicated for treatment of BDBV or SUDV infection. Identification of mAbs that cross-neutralize EBOV, BDBV, and SUDV with high potency is challenging due to the relatively high antigenic variability between these viruses (King et al., 2019). The efficacy of previously reported investigational antibody therapeutics typically is limited to only one of the three medically important ebolavirus species. The nature of future ebolavirus outbreaks cannot be predicted, however, and in a scenario of global spread viruses can mutate rapidly making available antibody treatments vulnerable to escape, as has been recently shown for SARS-CoV-2 (Starr et al., 2021; Wang et al., 2021). One approach could be to develop separate therapeutic antibody products for BDBV or SUDV or future escape variants of EBOV. It is desirable from a practical standpoint, however, to identify a single broad therapeutic spectrum antibody treatment of an equivalent or higher potency to existing

93 monospecific antibody treatments that could be used for treatment of EBOV, BDBV, or SUDV. 
94 Therefore, ongoing efforts are needed to increase the therapeutic breadth of antibody therapies while maintaining or improving efficacy.

The ebolavirus envelope contains a single surface protein, the glycoprotein (GP), which is the key target for neutralizing mAbs (King et al., 2018; Lee et al., 2008; Lee and Saphire, 2009; Misasi and Sullivan, 2021). We previously described isolation of two broadly neutralizing human antibodies designated EBOV-515 and EBOV-442 using a human B cell hybridoma approach (Gilchuk et al., 2018a). Each of these two mAbs exhibited favorable immunological profiles, which included (1) broad reactivity for binding to GP of diverse species (EBOV, BDBV, and SUDV), (2) broad neutralization of authentic ebolaviruses (EBOV, BDBV, and SUDV), (3) recognition of distinct, non-overlapping epitopes in the GP (EBOV-515 is basespecific, and EBOV-442 is glycan-cap-specific), and (4) a high level of therapeutic protection against EBOV in mice. The antibodies EBOV-515 or EBOV-442 are analogous to the broadlyreactive mAb EBOV-520 (GP-base-specific mAb) or mAb EBOV-548 (glycan-cap-specific), respectively. We recently described a beneficial feature of the combination of EBOV-520+ EBOV-548 by showing that these two antibodies synergized for virus neutralization when combined in a cocktail and conferred therapeutic protection in EBOV-challenged rhesus macaques (Gilchuk et al., 2020b). We did not previously characterize the similar combination of EBOV-515 + EBOV-442. However, our previous studies revealed that the individual antibodies EBOV-515 and EBOV-442 had higher potency to neutralize the most antigenically distinct of the three viruses (SUDV) when compared, respectively, to the potency of EBOV-520 or EBOV548. Also, EBOV-515 monotherapy in mice demonstrated a high level of therapeutic protection against SUDV (Gilchuk et al., 2018a; Gilchuk et al., 2020b). Given the higher potency of rEBOV-515 and rEBOV-442 against SUDV, we suggested their combination as a candidate for a "next-generation" broad therapeutic antibody cocktail. In this study we described pre-clinical development of the EBOV-515 + EBOV-442 antibody cocktail and defined the molecular basis for its pan-ebolavirus activity and efficacy. 


\section{Results}

Activities of pan-ebolavirus candidate cocktail containing recombinant antibodies rEBOV-442 and rEBOV-515.

Antibody variable gene sequences for mAbs EBOV-515 and EBOV-442 were determined, and synthetic DNAs encoding the mAbs were used to produce recombinant IgG1 in transiently-transfected Chinese hamster ovary (CHO) cells. Recombinant (r) mAbs designated as rEBOV-515 and rEBOV-442 potently neutralized EBOV, BDBV, and SUDV (Figure 1A) with a note that rEBOV-442 was more active against Boniface variant of SUDV (see below). To assess the Fc-mediated effector function of these antibodies to mediate killing of antigenexpressing cells, we used a stably-transfected EBOV GP-expressing SNAP-tagged 293F cell line as a target, with heterologous human PBMCs as source of effector cells and a previously described assay (Domi et al., 2018). The glycan-cap-specific antibody rEBOV-442 IgG1 exhibited a high level of cytotoxic activity, and the GP-base-specific antibody rEBOV-515 exhibited a moderate level of cytotoxic activity, relative to the control Fc-function-disabled IgG1-LALA-PG variant of rEBOV-515 (designated as rEBOV-515 LALA-PG) or an irrelevant antibody rDENV 2D22 (IgG1 isotype) specific to the dengue virus envelope (E) protein (Fibriansah et al., 2015) (Figure 1B). Neutralizing activity of the wild-type IgG1 and IgG1LALA-PG variants of rEBOV-515 was equivalent (Figure S1A). These results taken together revealed two complementary activities exhibited by this broad antibody cocktail, specifically the Fc-mediated effector functions mediated by rEBOV-442 and the potent neutralizing activities mediated by rEBOV-442 and rEBOV-515 (Figure 1C).

One benefit of using a cocktail of two or more neutralizing antibodies that bind to nonoverlapping regions of the viral antigen is to reduce the risk of viral escape from neutralization that is inherent in monotherapy approaches (Baum et al., 2020; Misasi and Sullivan, 2021; Yewdell et al., 1979). To demonstrate this feature for this cocktail directly, we next used a recombinant infectious vesicular stomatitis virus (VSV) expressing EBOV GP in place of the endogenous VSV glycoprotein (VSV/EBOV GP) to select for GP mutations that escape antibody neutralization. We assessed rEBOV-442, rEBOV-515, or 1:1 mixture of both antibodies (half maximal inhibitory concentration $\left[\mathrm{IC}_{50}\right]<1.5 \mu \mathrm{g} / \mathrm{mL}$ against $\mathrm{EBOV}$ for individual $\mathrm{mAbs}$ and the cocktail) and used a high-throughput quantitative real-time cellular analysis assay (RTCA) to select viral variants that can escape neutralization (Gilchuk et al., 2020b; Greaney et al., 2021). 
We selected for escape at a single saturating antibody concentration of $20 \mu \mathrm{g} / \mathrm{mL}$ using 20,000 plaque forming units of VSV/EBOV GP per well ( $\sim 1$ multiplicity of infection [MOI]) and performing 60 replicates for each sample (Figure 1D). For rEBOV-442, this process selected viral variants that we confirmed escaped neutralization at $20 \mu \mathrm{g} / \mathrm{mL}$ of rEBOV-442 but were neutralized by rEBOV-515 or a mixture of rEBOV-442 and rEBOV-515 (Figure 1D, S2B). We sequenced the viral gene encoding the GP of rEBOV-442-selected escape viruses and identified seven distinct point mutations, including the previously identified escape mutation L273P (Gilchuk et al., 2018a) that appeared in all sequenced escape viruses in this study (Figure 1D). The escape mutation L273P likely pre-existed in the virus stock at a low frequency explaining the observed rate of escape from rEBOV-442 neutralization. In all cases, escape viruses carried GP mutations in the binding site of rEBOV-442 (Figure S1C). For rEBOV-515 or the cocktail, escape variants were not detected in any of the 60 replicate experiments (Figure 1D). Together these results demonstrated a high resistance to viral escape for the cocktail of the two broad antibodies rEBOV-442 and rEBOV-515, which acts by both neutralizing and Fc-mediated

Differential requirements for the Fc regions of antibodies $\mathrm{rEBOV}-442$ and $\mathrm{rEBOV}$ 515 for therapeutic protection in mice.

To define the contribution of Fc-mediated effector functions to protection in vivo, each $\mathrm{mAb}$ of the candidate therapeutic cocktail was assessed as an IgG1 protein (the original subclass of antibody secreted by the hybridoma cell line and a functionally competent form of $\mathrm{mAb}$ ) and as IgG1 LALA-PG protein (which is disabled for Fc function and fully silent in mice). We challenged groups of mice with mouse-adapted EBOV (EBOV-MA) on day 0 and administered antibodies 1 day later. Previously we have shown that for low-dose treatment $(1 \mathrm{mg} / \mathrm{kg})$, the Fcdisabled LALA variant of the GP base-specific mAb EBOV-520 offered a higher level of therapeutic protection in mice against EBOV (60\% survival) when compared to that mediated by the wild-type (wt) IgG1 EBOV-520 (0\% survival; (Kuzmina et al., 2018)). In a new study conducted here, the rEBOV-515 LALA-PG antibody variant offered complete protection (100\% survival) against EBOV challenge in mice at a $1 \mathrm{mg} / \mathrm{kg}$ therapeutic dose, while the $w t$ IgG1 variant showed partial protection (80\% survival) (Figure 2). This finding demonstrated a higher in vivo potency of the broad GP base-specific mAb rEBOV-515 when compared to the 
previously reported effect of the broad GP base-specific mAb rEBOV-520, and suggested that rEBOV-515 LALA-PG is a preferable Fc variant for the cocktail of two Fc variants tested. Similarly, we compared the in vivo potency of $w t$ IgG1 rEBOV-442 and rEBOV-442 LALA-PG, which were administered at a $5 \mathrm{mg} / \mathrm{kg}$ dose one day after EBOV challenge (Figure 2). Cytotoxicity assay results (Figure 1B) suggested that the glycan cap antibody rEBOV-442, in addition to possessing neutralizing activity, also exhibited substantial Fc effector functionmediated activity. In agreement with this finding, the results of our in vivo study showed a transient (2-4 days post-infection) improvement in weight (i.e., reduced loss) with wt rEBOV442 IgG1, which was associated with improved protection (100\% survival in the $w t$ antibodytreated group when compared to $80 \%$ in the rEBOV-442 LALA-PG-treated group) (Figure 2). Together, these data revealed differing requirements for the Fc regions of rEBOV-442 and rEBOV-515, demonstrated a high in vivo potency of the antibodies tested, and justified the inclusion of rEBOV-515 as a LALA-PG variant and rEBOV-442 as a $w t$ IgG1 variant in a new broad and protective ebolavirus two-antibody cocktail.

\section{Synergistic activity of antibodies $\mathrm{rEBOV}-442$ and $\mathrm{rEBOV}-515$ in the cocktail.}

Antibodies in a cocktail directed to a common viral protein may recognize antigen in a synergistic, additive, or antagonistic manner. We first characterized the effect mediated by the mixture of two antibodies on ebolavirus GP binding. Serially-diluted Alexa-Fluor-647-labeled antibody rEBOV-442 IgG1 or rEBOV-515 LALA-PG was titrated into serially-diluted unlabeled partner antibody to generate two pairwise combinatorial matrices of two antibodies in the mixture (Figure S2A, B). Binding of the Alexa-Fluor-647-labeled antibody from each combination was assessed by flow cytometric analysis using a Jurkat cell line that was stably transduced to display EBOV GP on the surface as described before (Gilchuk et al., 2020b). The values were calculated as the percent of the relative fluorescence signal caused by the highest concentration of respective fluorescently-labeled antibody alone (Figure S2A, B), and then

214 et al., 2020). The synergy score can be interpreted as the average excess response (percent 215 change) for an antibody combination (Ianevski et al., 2020). The comparison revealed that the 216 combination of antibodies rEBOV-442 and rEBOV-515 was synergistic, and each antibody 217 reciprocally enhanced binding of the partner antibody in the mixture (Figure S2B, C). This 
218 finding contrasted with the unidirectional GP binding synergy observed in the cocktail of the 219 other broad antibodies rEBOV-520 and rEBOV-548 (Gilchuk et al., 2020). Binding enhancement 220 increased steadily with increasing of antibody concentration, indicating more contribution from 221 synergy at higher concentrations of individual Abs in the cocktail (Figure S2B, C).

We next characterized the effect by the mixture of two antibodies on ebolavirus neutralization. Using a recently developed real-time cell analysis (RTCA) cellular impedance assay that quantifies virus-induced cytopathic effects and infectious chimeric VSV/ebolavirus GP viruses (Gilchuk et al., 2020a; Gilchuk et al., 2020b), we showed efficient and dosedependent neutralization of VSV/EBOV-GP, /BDBV-GP, or /SUDV-GP viruses by the 1:1 antibody mixture (Figure 3A). Then, we titrated serially-diluted rEBOV-442 into serially-diluted rEBOV-515 to generate a pairwise combinatorial matrix of two antibodies in the mixture and assessed each combination for neutralization of VSV/EBOV-GP, /BDBV-GP, or /SUDV-GP viruses (Figure 3B). Data were analyzed using the ZIP synergy scoring model. This analysis identified areas in the neutralization matrix (showing mAb ratios) with the most profound combination effect and suggested broad synergistic activity in the cocktail for the mixture of rEBOV-442 and rEBOV-515 (Figure 3C).

\section{Protective pan-ebolavirus combination therapy of nonhuman primates by} antibodies rEBOV-442 and rEBOV-515.

Next, we tested the efficacy of the cocktail of rEBOV-515 LALA-PG + rEBOV-442

IgG1 in nonhuman primate (NHP) challenge models for each of the three ebolaviruses, EBOV (Kikwit variant), BDBV (Uganda variant), and SUDV (Gulu variant). We used rhesus macaque EBOV and SUDV lethal challenge models and a cynomolgus monkey BDBV lethal challenge model, which recapitulate many key features of EVD in humans (Bennett et al., 2017; Geisbert et al., 2015). Animals were assigned to three treatment groups of five animals per group. After intramuscular challenge with a lethal target dose of 1,000 plaque-forming units (PFU) of EBOV,

244 BDBV, or SUDV, all NHPs of the treatment group received intravenously two $30 \mathrm{mg} / \mathrm{kg}$ doses of the cocktail (a 2:1 mixture of rEBOV-515 LALA-PG and rEBOV-442 IgG1) spaced 3 days apart (given days 3 and 6 after EBOV, days 6 and 9 after BDBV, or days 4 and 7 after SUDV inoculation). We chose a 2:1 antibody ratio in the cocktail based on the high level of synergy identified for this antibody ratio from the in vitro synergy distribution maps (Figure 3; S2) and 
249 due to higher neutralizing potency of rEBOV-515 against SUDV when compared to the potency 250 of rEBOV-442 (Figure 1A). For each challenge cohort, an additional animal was studied as a contemporaneous control and was left untreated. The untreated control animals developed a high clinical score and succumbed to disease on day 6,14 , or 10 after viral challenge with EBOV, BDBV, or SUDV, respectively. The two-dose therapeutic cocktail treatment provided complete pan-ebolavirus protection of NHPs from mortality and clinical signs of EVD (Figure 4A, B). We next assessed changes in blood chemistries and blood cell composition that are typically associated with EVD to further characterize the efficacy of the mAb cocktail treatment (Tables S1-6). The liver enzymes alkaline phosphatase (ALP) and gamma glutamyl transferase (GGT), which are indicators of EVD (Qiu et al., 2014), were elevated in untreated NHPs at the peak of the disease (Figure 4B, C). Treated animals did not show signs of acute liver injury after the treatment, displaying low amounts of ALP, GGT, creatinine (CRE), and the other blood chemistries when compared with those of untreated NHP (Figure 4C; Tables S4-6).

At the time of first treatment with the cocktail (day 3 after EBOV, day 6 after BDBV, or day 7 after SUDV inoculation), 14 NHPs from the treatment-designated group (all except one animal in EBOV-challenged group) and the control untreated NHPs were viremic, with virus titers that ranged from 5.1 to $10.6 \log _{10}$ genome equivalents (GEQs) per $\mathrm{mL}$ of plasma, as measured by quantitative reverse-transcription PCR (qRT-PCR) (Figure 5A). A plaque assay that detects infectious virus revealed viremia in all 18 animals, with viral titers ranging from 0.7 to $7.4 \log _{10}$ plaque forming units (PFU) per $\mathrm{mL}$ of plasma at the time of first treatment with the cocktail (Figure 5B). This finding confirmed active ebolavirus infection in all NHPs before treatment. At the time of the second antibody cocktail treatment (day 6 after EBOV, days 9 after BDBV, or day 7 after SUDV inoculation), each untreated control NHP from a respective EBOV, BDBV, or SUDV challenge cohort developed high viremia $>8 \log _{10} \mathrm{GEQ} / \mathrm{mL}$ and $>5 \log _{10}$ $\mathrm{PFU} / \mathrm{mL}$ (Figure 5 A, B). Concordant with full protection from disease and death, none of the 15 treated NHPs had detectable infectious virus in the plasma at that time (limit of detection [LOD]

$275=5 \mathrm{PFU} / \mathrm{mL}$ ), and viral genomes were not detected in 12 of those NHPs $3.7 \log _{10} \mathrm{GEQ} / \mathrm{mL}$ at 276 that time (Figures 4, 5). The three remaining NHPs that were from the BDBV inoculation cohort 277 and that showed slightly delayed clearance of viral genomes in plasma no longer had detectable 278 virus by day 15 after viral challenge. Analysis of various tissues harvested at study endpoint 
with BDBV) and untreated animals (day 6, 14, or 10 after inoculation with EBOV, BDBV, or

SUDV, respectively) confirmed virologic protection mediated by the cocktail treatment (Figure S3).

Together these results showed a high therapeutic efficacy of the cocktail of rEBOV-515 LALA-PG + rEBOV-442 IgG1 to treat and revert disease caused by primary ebolaviruses that are responsible for outbreaks in humans - EBOV, BDBV, and SUDV.

Structural basis for the efficacy and broad ebolavirus neutralization by the cocktail.

We previously reported the molecular determinants of the GP binding for several glycan cap-specific antibodies, including the broad antibody rEBOV-442 (Murin et al., 2021), and defined the structural basis of synergy for the pair of broad antibodies rEBOV-520 and rEBOV548 (Gilchuk et al., 2020b). In this new study, we focused on studies of the determinants of rEBOV-515 binding to elucidate the structural basis for the neutralization breadth and efficacy mediated by pan-ebolavirus cocktail of rEBOV-515 + rEBOV-442. We generated a complex of both rEBOV-515 and rEBOV-442 Fab with mucin-deleted EBOV GP from the Makona variant (EBOV GP $\triangle \mathrm{Muc} / \mathrm{Mak}$ ) and solved structures by cryogenic electron microscopy (cryo-EM) (Table S7; Figure 6A and S4).

The interface between GP and rEBOV-515 in this structure was resolved to $\sim 3$ to $3.5 \AA$ resolution (Figure S4), allowing for confident modeling of most of the side-chain residues. rEBOV-515 binds to the base of the internal fusion loop (IFL), directly below the glycan cap in GP1 (Figure 6A). There is significant overlap of the rEBOV-515 epitope with that of rEBOV520, but rEBOV-515 has more extensive contacts in GP2 and less in GP1 (Figure 6B). Most EBOV-515 contacts are mediated by the heavy chain (HC), with all three complementarity determining regions (CDRs) contributing to binding the base of the IFL as well as a portion of GP1 near the $3^{10}$ pocket (Figure 6C; S5A-B, S6). The CDRH3 contributes the most extensive contacts, including those that displace the descending $\beta 17-\beta 18$ loop of the glycan cap, making contacts near the $3^{10}$ pocket, as well as a strong cation-pi bond with R136 $6_{\mathrm{GP} 1}$ (Figure 6C). The rEBOV-515 light chain (LC) also makes contacts with all three CDRs exclusively within GP2 complementary hydrophobic (Figure S5B) and electrostatic (Figure S5D) surfaces for binding to this epitope within GP. 
Neutralizing potency may depend on the ability of antibodies to remain bound to viral GP within the acidic environment of late endosomes, which is where $\mathrm{pH}$-dependent cleavage occurs to expose the Niemann-Pick C1 (NPC1) receptor binding site (Carette et al., 2011; Chandran et al., 2005). Given that rEBOV-515 strongly interacts with the EBOV GP, we assessed binding of this antibody at varying $\mathrm{pH}$ to recombinant EBOV, BDBV or SUDV GPs by ELISA. We used the broadly reactive base-specific antibody rEBOV-520 for comparison. rEBOV-515 and rEBOV-520 bound equivalently to the GP of each of the three ebolaviruses at neutral $\mathrm{pH} 7.4$, and rEBOV -515 remained bound at acidic $\mathrm{pH}$ of 5.5 or 4.5 , while rEBOV-520 lost binding activity (Figure S7A).

The rEBOV-515 binding site partially overlaps with those of other reported broad antibodies that bind to the $3^{10}$ pocket, including rEBOV-520 (Gilchuk et al., 2020b) and ADI15946 (West et al., 2019) (Figure 6B, E). Each of these antibodies relies upon E106 and R136 in GP1 and several residues at the base of the IFL, using long CDRH3 loops that mimic and replace the $\beta 17-\beta 18$ loop of the GP1 in apo-GP structure (Figure 6E). However, characterization of the rEBOV-515 binding site revealed several unique features. rEBOV-515 uses a single CDR loop to simultaneously mimic and displace the $\beta 17-\beta 18$ loop and to bind to R136 in GP1. This feature allows rEBOV-515 to access a region that is occupied by a glycerol cryoprotectant molecule in the unliganded crystal structure of GP (Protein Data Base [PDB] 5JQ3; 5JQB) that we defined as "glycerol pocket" (Figure 6E). In addition, this mechanism facilitates greater interaction of EBOV-515 with the cleavage loop compared to that caused by rEBOV-520, which may explain the high GP cleavage-inhibiting activity of EBOV-515 (Figure S7B). Further, a distinct pose of rEBOV-515 binding into the $3{ }^{10}$ pocket avoids clashes with the $\alpha 2$ helix of the glycan cap (Figure 6F), unlike the binding of rEBOV-520 to the GP, which requires the $\alpha 2$ helix shift (Gilchuk et al., 2020b). This finding suggested that the binding site of rEBOV-515 on the intact GP molecule is more accessible than the rEBOV-520 binding site, which could explain the higher neutralizing potency of rEBOV-515 when compared to the potency of rEBOV-520 against the virus carrying the intact GP. Of note, we have shown previously that GP cleavage, which removes the glycan cap along with the $\beta 17-\beta 18$ loop, resulted in enhanced binding to cell-surface-displayed cleaved GP and increased neutralizing potency for both rEBOV-515 and rEBOV-520 (Gilchuk et al., 2018a; Gilchuk et al., 2020b). 
There are notable differences in degree of pan-ebolavirus neutralization and protection by each of three reported broadly-reactive human antibodies despite recognition of partially overlapped epitopes they recognize on the GP base (Figure 6B). ADI-15946 did not fully neutralize most antigenically distinct SUDV (Wec et al., 2017; West et al., 2019), rEBOV-520 neutralized SUDV with modest potency but showed weak protection against SUDV in mice, and rEBOV-515 potently neutralized each of three viruses and protected against SUDV in mice (Gilchuk et al., 2018a; Gilchuk et al., 2020b). Our structural analysis allowed us to compare the epitope footprint and contacts for each of these antibodies in relation to sequence conservation between the three major ebolavirus (Figure 7; S6), providing insight that may help explain differences in neutralization breadth. ADI-15946 makes fewer contacts with GP1 but more contacts to the N-terminus of GP2, a region that is less conserved that may explain weak SUDV neutralization. Conversely, rEBOV-520 makes more extensive contacts with GP1, as this region is generally less conserved. $\mathrm{rEBOV}-515$ relies on minimal contacts with GP1, except in regions that are completely conserved, including R136 and E106. Taken together with a more conserved footprint, these observations provide a molecular basis for the superior breadth of neutralization and protection exhibited by rEBOV-515 over similar antibodies.

\section{Discussion}

Here we report comprehensive studies of a new pan-ebolavirus antibody combination treatment with a well-defined and complex molecular basis of broad neutralization and potency. The cocktail exhibited high therapeutic efficacy against all three medically important ebolaviruses in nonhuman primates. The discovery and recent approval of human antibody-based therapeutics represents a landmark achievement in the development of EVD medical countermeasures. The clinical trials in the DRC outbreak, however, highlighted substantial gaps remained in improving the treatment of acute EVD (Iversen et al., 2020). The greatest benefit of antibody treatment in patients was mainly in those receiving early therapy, and only moderate

367 benefit was observed in severely ill patients (Levine, 2019). Another remaining challenge for

368 implementation of the current regimens is the logistical complexity of intravenous drug administration in the field, which may limit widespread application of antibody therapy in future 370 outbreak scenarios. 
Given the difference in efficacy mediated by different antibody drugs that was observed for advanced EVD treatments, antibody potency likely is a key contributing determinant of treatment efficacy. Inmazeb and Ebanga demonstrated higher efficacy when compared to that of the antibody cocktail ZMapp ${ }^{\mathrm{TM}}$ in clinical trials (Levine, 2019). Inmazeb is a three-antibody cocktail based on REGN-EB3 antibody sequences (Pascal et al., 2018), Ebanga is a monotherapy based on the antibody mAb114 (Corti et al., 2016), and ZMapp ${ }^{\mathrm{TM}}$ is a cocktail of three murinehuman chimeric mAbs (Qiu et al., 2014). A comparison with the historical NHPs studies with REGN-EB3 (3 x $50 \mathrm{mg} / \mathrm{kg}$ dose at d5, 8, and 11 after exposure) (Pascal et al., 2018), $\mathrm{mAb} 114$ (3 x $50 \mathrm{mg} / \mathrm{kg}$ dose at d1, 2, and 3 after exposure) (Corti et al., 2016), and ZMapp ${ }^{\mathrm{TM}}$ (3 x $50 \mathrm{mg} / \mathrm{kg}$ dose at d3, 6, and 9 after exposure) (Qiu et al., 2014) suggested equivalent or likely higher potency of our EBOV-442 IgG1 + EBOV-515 LALA-PG cocktail treatment $(2$ x 30 $\mathrm{mg} / \mathrm{kg}$ at $\mathrm{d} 3$ and 6 after exposure) against homologous EBOV. More studies are needed to compare available treatments and to determine if increasing antibody therapeutic potency would benefit clinical outcomes in treatment of severely ill patients and/or allow for rapid and more practical treatment by an alternative (intramuscular or subcutaneous) route of antibody delivery. Anticipation of future EVD outbreaks requires consideration of therapeutic breadth. As an added feature, the two-antibody cocktail we describe here offered an increased therapeutic breadth that extended to protection against BDBV and SUDV in NHP models. One other investigational human mAb cocktail that demonstrated broad efficacy in NHPs, MBP134 ${ }^{\mathrm{AF}}$, has been described (Bornholdt et al., 2019). MBP134 ${ }^{\mathrm{AF}}$ is comprised of antibody ADI-15878 and a derivative of antibody ADI-15946 (defined as ADI-23774), which was engineered to improve its specificity against SUDV GP (Wec et al., 2019). A comparison of our results to the reported activities of ADI-15946 or ADI-23774 (Wec et al., 2017) indicates a high potency for the homologous base-specific antibody rEBOV-515 that we describe. In agreement with this functional assessment, our structural data showed that rEBOV-515 strongly interacts with conserved residues in the GP, with a unique footprint among base-specific broadly reactive human mAbs rEBOV-515, rEBOV-520, and ADI-15946, suggesting a structural basis for its remarkable breadth and potency. neutralizing potency and breadth (Saphire et al., 2018). Reports of human EVD cases revealed high plasma viral RNA titers at the time of patient admission into antibody treatment studies 
402 (Brown et al., 2018; Mbala-Kingebeni et al., 2019). Similarly, we observed high serum viral 403 titers in each cohort of challenged NHPs before antibody treatment (Figure 5), indicating that at 404 the time of treatment many cells in multiple organs are already infected. This finding highlights 405 the importance to retain Fc-mediated effector function activity in antibody cocktails in order to 406 preserve the ability to eliminate infected cells. In the cocktail of EBOV-442 IgG1 + EBOV-515 407 LALA-PG, the stronger and broader neutralizing antibody EBOV-515 LALA-PG may act 408 directly to neutralize circulating virus, and this activity is enhanced synergistically in the 409 presence of rEBOV-442 IgG1. Antibody rEBOV-442 IgG1, in addition to direct virus 410 neutralization, may act through Fc-mediated functions by binding to the non-overlapping 411 antigenic site on the GP on infected cells, and this activity could be enhanced reciprocally in the 412 presence of EBOV-515 LALA-PG. Such a combination of activities may facilitate viral 413 clearance and potentially decrease the likelihood of viral mutations that facilitate escape from the 414 cocktail treatment. The relative contribution of these activities to the therapeutic efficacy 415 exhibited by this cocktail needs further investigation.

416 During acute EVD, circulating infectious virus sometimes seeds immune-privileged

417 tissues, including the brain, eyes, and testes, and persist after clearance from the blood and 418 recovery (Diallo et al., 2016; Subtil et al., 2017; Varkey et al., 2015). Until recently, it was 419 generally assumed that Ebola epidemics start upon zoonotic transmission. On Feb 14, 2021, a 420 new EVD outbreak was declared in Guinea, and viral genome sequencing reports suggested that 421 the outbreak was caused by the Makona variant of EBOV that caused the 2014 EVD epidemics 422 (virological.org, 2021). The index case of the 2021 Guinea cluster likely was infected from a 423 persistent source, such as via sexual transmission from an EVD survivor (virological.org, 2021), 424 raising concerns about possible person-to-person transmission and reignition of outbreaks. The 425 existing therapies and those that are currently in clinical development should be evaluated for 426 their efficacy in clearing infectious virus from immune-privileged sites. Further, NHP studies 427 suggested a genetic drift upon selection pressure with sub-optimal antibody treatment that could 428 be a potential cause for failure during EVD treatment (Kugelman et al., 2015). Potent antibody 429 cocktails like EBOV-442 IgG1 + EBOV-515 LALA-PG may help thwart antigenic drift by 430 targeting non-overlapping vulnerable sites on GP and exhibiting complementary mechanisms of 431 action. 
In summary, these studies highlight the power of implementing a rational mAb cocktail development program using structure-function-guided principles (e.g., knowledge of binding sites, neutralization breadth, resistance to escape, multifunctionality, synergy etc.). We identified a pan-ebolavirus biologic comprising a two-antibody cocktail that exhibits high efficacy for treatment of all three medically important ebolaviruses with only two doses of mAb. These findings set the stage for clinical evaluation of pan-ebolavirus combination therapy with the two human antibodies rEBOV-442 IgG1 and rEBOV-515 LALA-PG.

\section{Limitations}

The protection of NHPs from advanced EVD using a lower dose of antibody cocktail treatment in a volume that can be delivered by the intramuscular or subcutaneous routes should

443 be assessed in future studies. The developability (manufacturability) of antibodies described here needs to be assessed in future studies. However, the results from our preclinical studies to date suggest favorable physiochemical profiles for these mAbs; both antibodies were stable for $>1$ month when stored at $4{ }^{\circ} \mathrm{C}$ and did not aggregate at $\mathrm{IgG}$ concentrations $>25 \mathrm{mg} / \mathrm{mL}$. Major sequence liabilities were not detected (except a longer than average CDRH3 of rEBOV-442) using online-based Therapeutic Antibody Profiler software

449 (http://opig.stats.ox.ac.uk/webapps/newsabdab/sabpred/tap). Both antibodies occurred naturally in response to ebolavirus infection in human survivors, with natural pairing of the heavy and light chains and isotypes (except LALA-PG modification for rEBOV-515) in their recombinant forms. rEBOV-442 and rEBOV-515 exhibited low or modest autoreactivity to human cells, respectively, as we recently reported (Murin et al., 2021).

\section{ACKNOWLEDGMENTS}

456 We thank D. Deer for technical assistance with NHP studies. We thank George K. Lewis, Robin

457 Flinko, and Chiara Orlandi for providing EBOV GPkik-293FS eGFP CCR5-SNAP cell line and 458 protocols for RFADCC assay. The Jurkat-EBOV GP cell line was a kind gift from C. Davis and R. 459 Ahmed. This work was supported by U.S. N.I.H. grants U19 AI109711 (to J.E.C. and A.B.), U19 460 AI142785 (to J.E.C. and T.G.), and U19 AI109762 (ABW), HHS contract HHSN272201400058C 461 (to J.E.C.), and DTRA grant HDTRA1-13-1-0034 (to J.E.C. and A.B.). J.E.C. is a recipient of the 4622019 Future Insight Prize from Merck KGaA, which supported this work with a grant. The project 
463 was supported by The Vanderbilt Institute for Clinical and Translational Research (VICTR) funded

464 by the National Center for Advancing Translational Sciences (NCATS) Clinical Translational

465 Science Award (CTSA) Program, Award Number 5UL1TR002243-03. The content is solely the

466 responsibility of the authors and does not necessarily represent the official views of the NIH. Work

467 in BSL-4 and ABSL-4 was supported by NIH grant 5UC7AI094660-07 and by the Animal Resource

468 Center of the Galveston National Laboratory.

469

470 AUTHOR CONTRIBUTIONS

471 P.G., C.D.M., R.W.C., R.C., A.B., T.W.G., A.B.W., and J.E.C. planned the studies. P.G., C.D.M., 472 R.W.C., P.A.I., K.H., V.B., K.N.A., J.B.G., N.K., T.A., R.S.N., R.E.S., N.S., S.J.Z., and R.G.B. 473 conducted experiments. P.G., C.D.M., R.W.C., A.B., T.W.G., A.B.W., and J.E.C. interpreted the 474 studies. P.G., C.D.M., and J.E.C. wrote the first draft of the paper. A.B., T.W.G., A.B.W, and J.E.C. 475 obtained funding. All authors reviewed, edited and approved the paper.

\section{DECLARATION OF INTERESTS}

J.E.C. has served as a consultant for Eli Lilly, GlaxoSmithKline and Luna Biologics, is a

479 member of the Scientific Advisory Boards of CompuVax and Meissa Vaccines and is Founder of

480 IDBiologics. The Crowe laboratory at Vanderbilt University Medical Center has received

481 unrelated sponsored research agreements from Takeda Vaccines, IDBiologics and AstraZeneca.

482 Vanderbilt University has applied for patents concerning ebolavirus antibodies that are related to 483 this work. All other authors declare no competing interests. 
Figure legends

Figure 1. Functional activities of pan-ebolavirus cocktail candidate antibodies rEBOV-442 and $\mathrm{rEBOV}-515$.

(A) EBOV, BDBV, or SUDV neutralization. Biosafety level 4 recombinant ebolaviruses encoding enhanced green fluorescent protein (eGFP) were incubated with increasing concentrations of recombinantly produced purified mAbs, and infection was determined at 3 days after inoculation by measuring eGFP fluorescence in cells. Mean \pm SD of technical triplicates from one experiment are shown.

494 (B) In vitro killing capacity mediated by the Fc regions of IgG1-engineered variants of mAbs measured by rapid fluorometric antibody-mediated cytotoxicity (RFADCC) assay. Human PBMCs (effector cells) were incubated with a SNAP-tagged EBOV GP-expressing 293F cell line as a target in the presence of increasing concentrations of purified recombinant mAbs, and cytotoxic activity was measured by flow cytometry. Dengue virus human antibody rDENV 2D22 served as a negative control. The dotted line indicates assay background. Mean \pm SD of technical duplicates from one experiment are shown.

501 (C) Heat map summarizing reactivity breadth and potency of rEBOV-442 and rEBOV-515. * 502 indicates data determined in our previous work using hybridoma-cell-secreted mAbs (Gilchuk et 503 al., 2018).

504 (D) Results of viral selections with individual antibodies or the cocktail, indicating the number of

505 replicates with escape out of total number tested, resistance of selected escape variants to

506 individual antibodies or the cocktail, and the selected mutations in the GP that escape

507 neutralization by rEBOV-442. The escape selection was performed using infectious chimeric

508 VSV expressing EBOV (Mayinga variant) GP. ** indicates the prevalent mutation L273P that

509 was identified in all sequenced escape viruses.

510 See also Figure S1.

512 Figure 2. Differential requirements for the Fc regions of antibodies $\mathrm{rEBOV}-442$ and 
514 C57BL/6 mice were challenged with mouse-adapted EBOV-MA, treated at 1 dpi with wild-type

515 IgG1 or the Fc-effector function disabled IgG1 LALA-PG variant of antibodies rEBOV-442 (5

$516 \mathrm{mg} / \mathrm{kg})$ and $\mathrm{rEBOV}-515(1 \mathrm{mg} / \mathrm{kg})$, and monitored for 28 days.

517 (A) Kaplan-Meier survival plot. The overall difference in survival between the groups was

518 estimated using two-sided log-rank (Mantel-Cox) test.

519 (B) Weight change.

520 (C) Clinical score. +, animal found dead prior to reaching the pre-determined clinical score.

521 Mean values are shown in (B-C), and data represent one experiment with five mice per

522 group. Dengue virus-specific antibody rDENV 2D22 was used as a control. A historical control

523 for protection from weight loss with $5 \mathrm{mg} / \mathrm{kg}$ of wild-type $\mathrm{rEBOV}-515$ treatment (dotted line in

524 B) is shown for comparative purposes.

Figure 3. Broad and synergistic neutralizing activity mediated by the cocktail of rEBOV442 and rEBOV-515. Neutralizing activity of individual antibodies or their mixture was assessed using infectious chimeric VSV expressing EBOV (Mayinga variant), BDBV (Uganda variant), or SUDV (Boniface variant) GP and real-time cell analysis (RTCA) assay. alone, rEBOV-515 alone, or a 1:1 mixture of rEBOV-442 and rEBOV-515. pairwise combinatorial matrix of two antibodies in the mixture. The matrix shows neutralization dose-response data for VSV/EBOV GP, VSV/BDBV GP, or VSV/SUDV GP, by indicated concentrations of rEBOV-442 and rEBOV-515. Axes denote the concentration of each antibody, with the percent neutralization shown in each square. The heat map denotes a gradient of 0 (white) to $100 \%$ (red) neutralization. Examples of neutralization by rEBOV-515 alone (raspberry box) or rEBOV-442 alone (blue box) in comparison to a combined indicated concentration of two mAbs in the cocktail (green box) are shown.

(C) Synergy distribution map generated from the dose-response neutralization matrix in (B). Red

542 the area of maximum synergy between the two monoclonal antibodies, and the $\delta$-score for this

543 area is shown. The $\delta$-score is a synergy score: values $<-10$ indicate antagonism; values -10 to 10 
544 indicate an additive effect; values $>10$ indicate synergy. Data in (A-C) are from a representative

545 experiment performed in technical duplicate and repeated twice.

546 See also Figure S2.

Figure 4. The cocktail treatment provides pan-ebolavirus protection of nonhuman primates against disease.

Rhesus macaques were inoculated with a lethal dose of the EBOV Kikwit or SUDV/Gulu viruses intramuscularly (i.m.) on day 0 and were treated with total $30 \mathrm{mg} / \mathrm{kg}$ of the cocktail (1:2 mixture of rEBOV-442 and rEBOV-515) intravenously on 3 and 6 dpi (EBOV/Kikwit; $\mathrm{n}=5$ per cohort), or 4 and 7 dpi (SUDV/Gulu; $\mathrm{n}=5$ per cohort). Cynomolgus monkeys were inoculated with a lethal dose of the BDBV/Uganda i.m. on day 0 and were treated with a total dose of $30 \mathrm{mg} / \mathrm{kg}$ of the cocktail (1:2 mixture of rEBOV-442 and rEBOV-515) intravenously on 6 and 9 dpi (n $=5$ per cohort). The contemporaneous control was an untreated NHP challenged with the virus ( $\mathrm{n}=$ 1 for each cohort). One experiment was performed. comparative purposes (see Methods). The proportion surviving at day 28 after viral challenge in the treated cohort was compared to the respective historical untreated cohort using a 2-sided exact unconditional test of homogeneity.

(B) Clinical score.

(C) Selected blood chemistry measurements: ALP, alkaline phosphatase; GGT, gamma-glutamyl transpeptidase; CRE, creatinine. Antibody treatment times are indicated with blue dotted vertical lines. Orange curves indicate treated, and black indicate untreated animals in (A) to (C). The

567 See also Tables S1-6.

Figure 5. The cocktail treatment provides pan-ebolavirus protection of nonhuman primates

571 Blood viral loads were assessed from individual animals that were challenged with

$572 \mathrm{EBOV} / \mathrm{Kikwit,} \mathrm{BDBV/Uganda,} \mathrm{or} \mathrm{SUDV/Gulu} \mathrm{and} \mathrm{treated} \mathrm{with} \mathrm{the} \mathrm{two-antibody} \mathrm{cocktail} \mathrm{as}$ 573 described in Figure 4.

574 (A) Kinetics of blood viral load determined for genome equivalents (GEq) using qRT-PCR. 
575 (B) Kinetics of infectious virus blood viral load as determined by plaque assay. Orange curves

576 indicate treated, and black indicate untreated animals. Antibody treatment times are indicated

577 with blue dotted vertical lines. The black dotted line indicates the limit of detection (LOD),

578 which was $3.7 \log _{10} \mathrm{GEq} / \mathrm{mL}$ (A) or $5 \mathrm{PFU} / \mathrm{mL}$ (B).

579 Each measurement in (A-B) represents the mean of technical duplicates.

580 See also Figure S3.

Figure 6. rEBOV-515 binds to the major site of vulnerability in the GP base region in a distinct manner.

(A) Cryo-EM structure of rEBOV-442 (heavy chain in blue and light chain in grey) and rEBOV515 (heavy chain in maroon and light chain in pink) Fab bound to EBOV GP $\Delta$ Muc/Mak. A side view in relation to the viral membrane is shown. Fab constant domains were excluded by masking.

(B) The predicted contact surface of broadly neutralizing antibodies rEBOV-515 and rEBOV520 on the surface representation of the EBOV GPAMuc/Mak monomer model (PDB: 5JQ3). Non-overlapping contact surfaces for rEBOV-515 or rEBOV-520 are shown, respectively, in maroon or orange, and overlapping contact surface of both antibodies is shown in yellow. (C) Contact residue details of the rEBOV-515 heavy chain Fab interactions with the base of GP. CDRH3 contacts include a backbone-mediated hydrogen bond at $\mathrm{S} 102_{\mathrm{H} 3}$ to $\mathrm{N} 512_{\mathrm{GP} 2}$, a key contact that links the $\beta 17-\beta 18$ loop to the base of the IFL via W291 in unliganded GP1. Contacts near the $3{ }^{10}$ pocket include a potential hydrogen bond between $\mathrm{S} 105_{\mathrm{H} 3}$ and $\mathrm{E} 106_{\mathrm{GP} 1}$ that forms when a large portion of the CDRH3 loop displaces the $\beta 17-\beta 18$ loop. Within the CDRH2 loop, $\mathrm{Y} 52_{\mathrm{H} 2}$ and $\mathrm{Y}^{5} 5_{\mathrm{H} 2}$ make potential hydrogen bonds via their hydroxyl groups to $\mathrm{H} 549_{\mathrm{GP} 2}$ or $\mathrm{H} 516_{\mathrm{GP} 2}$ on GP2, respectively. One of the most extensive rEBOV-515 contacts is from $\mathrm{W} 103_{\mathrm{H} 3}$,

600 bonds with $\mathrm{Y}_{3} 4_{\mathrm{H} 1}$ and a salt bridge with $\mathrm{E} 106_{\mathrm{H} 3}$.

601 (D) Epitope details of the rEBOV-515 light chain interactions with the base of GP. The rEBOV-

602515 light chain makes contacts with all three CDRs exclusively within GP2. Contact features 603 include a potential hydrogen bond between N32 1 and the backbone of $\mathrm{C} 511_{\mathrm{GP} 2}$, and a salt bridge

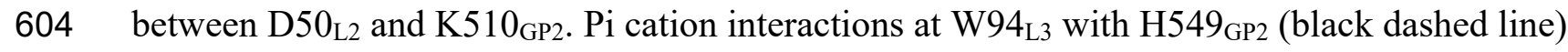


and an additional potential hydrogen bond at $\mathrm{N} 92_{\mathrm{L} 3}$ with $\mathrm{N} 550_{\mathrm{GP} 2}$ provide additional stabilizing interactions.

(E) Comparison of antibody CDRH3 loops that bind in and around the $3^{10}$ pocket (blue dashed circle) and putative glycerol pocket (solid yellow line). rEBOV-520 and ADI-15946 replace and mimic residue $\mathrm{W} 291_{\mathrm{GP} 1}$ (that anchors down the $\beta 17-\beta 18$ loop in apo-GP) with a tryptophan from their CDRH3 loops. rEBOV-515 uses an analogous tryptophan residue (W103 $\left.{ }_{\mathrm{H} 3}\right)$ to contact

611 R136 $6_{\mathrm{GP} 1}$ via a strong cation-pi interactions bond, which causes a shift in the rotamer of R136 $6_{\mathrm{GP} 1}$

$612 \mathrm{~W}_{103} \mathrm{H}_{3}$ from rEBOV-515 also accesses a pocket that is occupied by a glycerol cryoprotectant 613 molecule in the unliganded crystal structure of GP, which is also occupied by Y28 $8_{\mathrm{L} 1}$ from ADI61415946.

615 (F) A shift in the placement of the GP1 $\alpha 2$ helix that cased by the CDRH3 from rEBOV-520 but 616 is lacking in rEBOV-515 binding due to a shorter CDR loop is shown. Red dotted lines:

617 hydrogen bonds; green dashed lines: salt bridge; purple dashed line: cation-pi interaction; black 618 dashed line: carbon-pi or aromatic interactions. rEBOV-520-GP PDB: 6UYE; ADI-15946-GP 619 PDB: 6MAM.

620 See also Figures S4-6 and Table S7.

625 The corresponding antibody footprints are highlighted. On the right are aligned sequences of the 626 interacting regions on GP from the three major ebolaviruses, EBOV, BDBV, and SUDV. Total

627 contacts for each residue at $4 \AA$ distance or less were determined (see Table S7) and residues are 628 highlighted in blue according to the number of contacts, with darker blue indicating more 629 contacts and thus a higher likelihood for contributing critically to binding. Residues that are 630 variable are marked with a green diamond. HC contacts are indicated below in dark purple and 631 LC contacts in pink. 
STAR METHODS

634 Detailed methods include the following:

635 KEY RESOURCES TABLE

636 LEAD CONTACT AND MATERIALS AVAILABILITY

637 EXPERIMENTAL MODEL AND SUBJECT DETAILS

638 - Cell lines

$639 \quad$ Viruses

640 - Mouse models

641 - NHP model

642 METHOD DETAILS

643 - Monoclonal antibody production and purification

644 - GP expression and purification

645 - ELISA binding assay

646 - Mammalian cell-surface-displayed GP antibody binding

647 - Measurement of synergistic GP binding by a combination of antibodies

648 - Selection of VSV/EBOV GP mutants that escape antibody neutralization

649 - Neutralization assays

650 - Measurement of synergistic virus neutralization by a combination of antibodies

651 - Rapid fluorometric antibody-mediated cytotoxicity assay (RFADCC)

652 - GP cleavage inhibition

653 - Mouse challenge

654 - NHP challenge

655 - Measurement of virus load in NHP blood or tissues

656 - NHP serum biochemistry

657 - Sample preparation for cryogenic electron microscopy

658 - Cryogenic electron microscopy data collection and processing

659 - Cryogenic electron microscopy model building and refinement

660 QUANTIFICATION AND STATISTICAL ANALYSIS

661 DATA AND CODE AVAILABILITY

662 
LEAD CONTACT AND MATERIALS AVAILABILITY

664 Further information and requests for resources and reagents should be directed to and will be fulfilled by the Lead Contact, James E. Crowe, Jr. (james.crowe@vumc.org). Materials described in this paper are available for distribution under the Uniform Biological Material Transfer Agreement, a master agreement that was developed by the NIH to simplify transfers of biological research materials.

\section{EXPERIMENTAL MODEL AND SUBJECT DETAILS}

\section{Cell lines}

672 Vero-E6 (monkey, female origin) and Vero CCL-81 (monkey, female origin) were obtained from the 673 American Type Culture Collection (ATCC). Vero-E6 cells were cultured in Minimal Essential

674 Medium (MEM) (Thermo Fisher Scientific) supplemented with 10\% fetal bovine serum (FBS;

675 HyClone) and $1 \%$ penicillin-streptomycin in $5 \% \mathrm{CO}_{2}, 37^{\circ} \mathrm{C}$. Vero CCL-81 cells were cultured in

676 Dulbecco's Modified Eagle Medium (DMEM; Thermo Fisher Scientific)

677 supplemented with 10\% Ultra-Low IgG FBS (Gibco), $25 \mathrm{mM} \mathrm{HEPES,} \mathrm{and} 100$ units/mL of 678 penicillin, and $100 \mu \mathrm{g} / \mathrm{mL}$ of streptomycin (GIBCO) in $5 \% \mathrm{CO}_{2}, 37^{\circ} \mathrm{C}$. A $293 \mathrm{~F}$ cell line (human, 679 female origin) stably-transfected to express SNAP-tagged EBOV GP was described previously 680 (Domi et al., 2018). ExpiCHO (hamster, female origin) and FreeStyle 293F (human, female origin) 681 cell lines were purchased from Thermo Fisher Scientific and cultured according to the 682 manufacturer's protocol. The Jurkat-EBOV GP (Makona variant) cell line stably transduced to 683 display EBOV GP on the surface (Davis et al., 2019) was a kind gift from Carl Davis (Emory 684 University, Atlanta, GA). All cell lines were tested on a monthly basis for Mycoplasma and found to 685 be negative in all cases.

\section{Viruses}

688 The mouse-adapted EBOV Mayinga variant (EBOV-MA, GenBank: AF49101) (Bray et al., 689 1998), authentic EBOV Mayinga variant expressing eGFP (Towner et al., 2005), the chimeric 690 infectious EBOV/BDBV-GP (GenBank: KU174137) and EBOV/SUDV-GP

691 (GenBank: KU174142) viruses expressing eGFP (Ilinykh et al., 2016), the infectious vesicular 692 stomatitis viruses rVSV/EBOV GP (Mayinga variant) (Garbutt et al., 2004), rVSV/BDBV GP 693 (Uganda variant) (Mire et al., 2013), or rVSV/SUDV GP (Boniface variant) (Geisbert et al., 
2008) expressing an ebolavirus GP that replaces VSV G protein were used for mouse challenge studies or neutralization assays. Viruses were grown and titrated in Vero cell monolayer cultures. Authentic ebolaviruses EBOV (Cross et al., 2016), BDBV (Towner et al., 2008), and SUDV (Thi et al., 2016) were used for NHP challenge studies. The EBOV isolate 199510621 (Kikwit variant) originated from a 65-year-old female patient who died on 5 May 1995. The study challenge material was from the second Vero-E6 passage of EBOV isolate 199510621. The first passage at UTMB consisted of inoculating CDC 807223 (passage 1 of EBOV isolate 199510621) at a MOI of 0.001 onto Vero E6 cells. SUDV isolate 200011676 (variant Gulu) originated from a 35-year-old male patient who died on 16 October 2000 . The study challenge material was from the second Vero-E6 cell passage of SUDV isolate 200011676. The first passage at UTMB consisted of inoculating CDC 808892 (CDC passage 1 of SUDV isolate 200011676) at a MOI of 0.001 onto Vero-E6 cells. BDBV isolate 200706291 variant Uganda originated from serum of a patient collected in Uganda on 1 October 2007. The study challenge material was from the second Vero-E6 cell passage of BDBV isolate 200706291 variant Uganda. Briefly, the first passage at UTMB consisted of inoculating CDC 811250 (CDC passage 1 of BDBV isolate 200706291) at a MOI of 0.001 onto Vero-E6 cells. The cell culture fluids were subsequently harvested at day 10 post inoculation with each of indicated viruses and stored at $80^{\circ} \mathrm{C}$ as $\sim 1 \mathrm{~mL}$ aliquots. Neither mycoplasma nor endotoxin were detected $(<0.5$ endotoxin units

$712(\mathrm{EU}) / \mathrm{mL})$.

\section{Mouse model}

715 Seven- to eight-week old female BALB/c mice were obtained from the Jackson Laboratory. Mice

716 were housed in microisolator cages and provided food and water ad libitum. Challenge studies were 717 conducted under maximum containment in an animal biosafety level 4 (ABSL-4) facility of the 718 Galveston National Laboratory, UTMB. The animal protocols for testing of mAbs in mice were 719 approved by the Institutional Animal Care and Use Committee of the University of Texas Medical 720 Branch (UTMB) in compliance with the Animal Welfare Act and other applicable federal statutes 721 and regulations relating to animals and experiments involving animals. 
724 Three- to four-year-old male $(n=6)$ or female $(n=6)$ rhesus macaques used in this study were

725 obtained from PrimGen. Four-year-old male $(n=3)$ or female $(n=3)$ cynomolgus monkeys were

726 obtained from Worldwide Primates. NHP research adhered to principles stated in the eighth edition

727 of the Guide for the Care and Use of Laboratory Animals (National Research Council, 2011). The

728 facility where this research was conducted [University of Texas Medical Branch (UTMB)] is fully

729 accredited by the Association for Assessment and Accreditation of Laboratory Animal Care

730 International and has an approved Office of Laboratory Animal Welfare Assurance (\#A3314-01).

732 METHOD DETAILS

\section{Monoclonal antibody production and purification}

734 Sequences of monoclonal antibodies that had been synthesized as cDNA (Twist Bioscience) and

735 cloned into an IgG1 or IgG1 LALA-PG monocistronic expression vector (designated as pTwist-

736 mCis_G1 or pTwist-mCis_hG1 LALA-PG) were used for monoclonal antibody secretion in

737 mammalian cell culture. This vector contains an enhanced 2A sequence and GSG linker that

738 allows the simultaneous expression of monoclonal antibody heavy and light chain genes from a

739 single construct upon transfection (Chng et al., 2015). CHO cell cultures were transfected using

740 the Gibco ExpiCHO Expression System protocols as described by the vendor. Culture

741 supernatants were purified using $5 \mathrm{~mL}$ HiTrap MabSelect SuRe (Cytiva, formerly GE Healthcare

742 Life Sciences) column and an ÄKTA pure chromatography system (Cytiva). Purified

743 monoclonal antibodies were buffer-exchanged into PBS, concentrated using Amicon Ultra-4 50-

$744 \mathrm{kDa}$ centrifugal filter units (Millipore Sigma) and stored at $4{ }^{\circ} \mathrm{C}$ until use. For NHP treatment

745 studies antibodies were purified from 5 to $15 \mathrm{~L}$ of CHO supernatant using HiScale 26/20 column

746 (Cytiva) packed with MabSelect SuRe resin, purified protein was buffer-exchanged into PBS

747 using HiScale 50/40 column packed with Sephadex G-25 (medium) resin (GE Healthcare Life

748 Sciences), concentrated, and stored at $-80{ }^{\circ} \mathrm{C}$ until use. Purified monoclonal antibodies were

749 tested routinely for endotoxin levels (found to be less than $30 \mathrm{EU}$ per $\mathrm{mg}$ IgG for mouse studies

750 and less than 1 EU per mg IgG for NHP studies). Endotoxin testing was performed using the

751 PTS201F cartridge (Charles River), with a sensitivity range from 10 to $0.1 \mathrm{EU}$ per mL, and an

752 Endosafe Nexgen-MCS instrument (Charles River). For structural studies, Fab was produced

753 after co-transfection of ExpiCHO cells with two separate mammalian expression vectors

754 containing antibody light chain and Fab heavy chain sequences as described previously (Gilchuk 
et al., 2020b). Fab proteins were purified using CaptureSelect column (Thermo Fisher

\section{GP expression and purification}

For ELISA studies, the ectodomains of EBOV GP $\triangle T M$ (residues 1-636; strain Makona; GenBank: KM233070), BDBV GP $\Delta$ TM (residues 1-643; strain 200706291 Uganda; GenBank: NC_014373), SUDV GP $\triangle T M$ (residues 1-637; strain Gulu; GenBank: NC_006432), and MARV GP $\Delta T M$ before (Gilchuk et al., 2018a). For structural studies, the ectodomain of EBOV/Makona GP (residues 32-644, GenBank AKG65268.1) lacking residues 310-460 of the mucin-like domain to produce EBOV/Makona GPAMuc was produced and purified as described before (Murin et al., 2021).

\section{ELISA binding assay}

To assess mAb binding at different $\mathrm{pH}$, wells of 96-well microtiter plates were coated with purified, recombinant EBOV, BDBV or SUDV GP $\triangle \mathrm{TM}$ ectodomains at $4^{\circ} \mathrm{C}$ overnight.

771 Plates were blocked with 2\% non-fat dry milk and 2\% normal goat serum in DPBS containing

$7720.05 \%$ Tween-20 (DPBS-T) for $1 \mathrm{~h}$. Purified mAbs were diluted serially in DPBS-T (pH 7.4), or

773 DPBS-T that was adjusted to $\mathrm{pH} 5.5$ or 4.5 with hydrochloric acid, added to the wells and

774 incubated for $1 \mathrm{~h}$ at ambient temperature. The bound antibodies were detected using goat anti-

775 human IgG conjugated with horseradish peroxidase (Southern Biotech) diluted in blocking

776 buffer. Color development was monitored using TMB (3,3',5,5'-tetramethylbenzidine) substrate

777 (Thermo Fisher Scientific), 1N hydrochloric acid was added to stop the reaction, and the

778 absorbance was measured at $450 \mathrm{~nm}$ using a spectrophotometer (Biotek).

\section{Mammalian cell-surface-displayed GP antibody binding}

781 Binding of Alexa Fluor 647-labeled antibody to Jurkat-EBOV GP cell line was assessed by flow

782 cytometry using an iQue Screener Plus high throughput flow cytometer (Intellicyt Corp.) as we 783 described previously (Gilchuk et al., 2020b). 
Serially-diluted Alexa Fluor 647-labeled antibody rEBOV-442 IgG1 or rEBOV-515 LALA-PG was titrated into serially-diluted unlabeled partner antibody to generate a pairwise combinatorial matrix of two antibodies in the mixture. For antibody dilutions and washes, we used DPBS (Dulbecco's phosphate-buffered saline) containing 2\% of heat-inactivated FBS and 2 mM EDTA (ethylenediaminetetraacetic acid, sodium salt) ( $\mathrm{pH}$ 8.0) designated as incubation buffer. For antibody staining, $\sim 5 \times 10^{4}$ Jurkat EBOV-GP cells were added per each well of V-bottom 96well plate (Corning) in $5 \mu \mathrm{L}$ of the incubation buffer, and antibody mixtures were added to the cells in duplicate for total volume of $50 \mu \mathrm{L}$ per well, followed by $2 \mathrm{hr}$ incubation at $4^{\circ} \mathrm{C}$. Cells were washed with the incubation buffer by centrifugation at $400 \times \mathrm{g}$ for $5 \mathrm{~min}$ at ambient temperature and binding to the GP was assessed using iQue Screener Plus flow cytometer. Data for up to 5,000 events per well were acquired, and data were analyzed with ForeCyt (Intellicyt Corp.) software. Dead cells were excluded from the analysis on the basis of forward and side scatter gate for viable cell population. Binding was calculated as the percent of the maximal median fluorescence intensity signal (MFI) by the highest concentration of respective fluorescently-labeled antibody alone $(25 \mu \mathrm{g} / \mathrm{mL})$. Synergy distribution maps were generated from the dose-response binding matrix using a web application, SynergyFinder 2.0, and data was analyzed using ZIP synergy scoring model (Ianevski et al., 2020).

\section{Selection and sequencing of VSV/EBOV GP mutants that escape antibody neutralization}

805 To screen for escape mutations selected in the presence of individual antibodies or antibody cocktails, we used a real-time cell analysis (RTCA) assay and XCELLigence RTCA MP Analyzer (ACEA Biosciences Inc.) with modification of recently described assays (Gilchuk et al., 2020a; Greaney et al., 2021). Fifty (50) $\mu \mathrm{L}$ of cell culture medium (DMEM supplemented with $2 \%$ FBS) was added to each well of a 96-well E-plate to obtain a background reading. Eighteen thousand $(18,000)$ Vero cells in $50 \mu \mathrm{L}$ of cell culture medium were seeded per each well, and plates were placed on the analyzer. Measurements were taken automatically every

$81215 \mathrm{~min}$ and the sensograms were visualized using RTCA software version 2.1.0 (ACEA

813 Biosciences Inc). VSV/EBOV GP virus (20,000 plaque forming units [PFU] per well, 1 MOI) 814 was mixed with a saturating neutralizing concentration of individual antibody $(10 \mu \mathrm{g} / \mathrm{mL})$ or two-antibody cocktail (1:1 antibody ratio, $10 \mu \mathrm{g} / \mathrm{mL}$ total antibody concentration) in a total volume of $100 \mu \mathrm{L}$ and incubated for $1 \mathrm{~h}$ at $37^{\circ} \mathrm{C}$. At $16-20 \mathrm{~h}$ after seeding the cells, the virus- 
817 antibody mixtures were added into 8 to 96 replicate wells of 96-well E-plates with cell

818 monolayers. Wells containing only virus in the absence of antibody and wells containing only

819 Vero cells in medium were included on each plate as controls. Plates were measured

820 continuously (every $15 \mathrm{~min}$ ) for $72 \mathrm{~h}$. The escape mutants were identified by delayed CPE in

821 wells containing antibody. To verify escape from rEBOV-442 antibody selection, isolated

822 viruses were assessed in a subsequent RTCA experiment in the presence of $20 \mu \mathrm{g} / \mathrm{mL}$ of rEBOV-

823442 or $20 \mu \mathrm{g} / \mathrm{mL}$ of rEBOV -515 or $20 \mu \mathrm{g} / \mathrm{mL}$ of $1: 1$ cocktail of rEBOV-442+rEBOV-515 (see

824 Figure S1B).

825

826 To verify escape mutations present in GP protein-expressing VSV antibody-selected escape

827 variants, the escape viruses isolated after RTCA escape screening were propagated in 6-well

828 culture plates with confluent Vero cells in the presence of $20 \mu \mathrm{g} / \mathrm{mL}$ of the rEBOV-442. Viral

829 RNA was isolated using a QiAmp Viral RNA extraction kit (QIAGEN) from aliquots of

830 supernatant containing a suspension of the selected virus population. The GP protein gene cDNA

831 was amplified with a SuperScript IV One-Step RT-PCR kit (Thermo Fisher Scientific) using

832 primers flanking the GP gene. The amplified PCR product $(\sim 2,400 \mathrm{bp})$ was purified using SPRI

833 magnetic beads (Beckman Coulter) at a 1:1 ratio and sequenced by the Sanger sequence

834 technique using primers giving forward and reverse reads of the glycan cap region of the GP.

836 Neutralization assays

837 BSL-4 virus neutralization assays were performed using recombinant EBOV-eGFP or chimeric

838 EBOV viruses in which GP was replaced with its counterpart from BDBV or SUDV, as

839 described previously (Ilinykh et al., 2016). Briefly, four-fold dilutions of the respective mAb

840 starting at $200 \mu \mathrm{g} / \mathrm{mL}$ were mixed in triplicate with $400 \mathrm{PFU}$ of the virus in U-bottom 96-well

841 plates and incubated for $1 \mathrm{hr}$ at $37^{\circ} \mathrm{C}$. Mixtures were applied on Vero-E6 cell monolayer cultures

842 in 96-well plates and incubated for four days at $37^{\circ} \mathrm{C}$. In the absence of $\mathrm{mAb}$ neutralizing

843 activity, the infection resulted in uniform eGFP fluorescence from the monolayer of cells that

844 was detected readily by fluorescence microscopy. Fluorescence was measured using Synergy HT

845 microplate reader (BioTek). Half maximal inhibitory concentration $\left(\mathrm{IC}_{50}\right)$ values were

846 determined by nonlinear regression analysis using Prism software. 
848 BSL-2 virus neutralization experiments were performed using the infectious rVSV/EBOV GP, $849 \mathrm{rVSV} / \mathrm{BDBV}$ GP, and rVSV/SUDV GP viruses, and we adopted high-throughput RTCA assay

850 that quantify virus-induced cytopathic effect (CPE) (Gilchuk et al., 2020a; Gilchuk et al., 2020b).

851 Viruses were pre-titrated by RTCA to determine dilution of each virus stock to achieve similar

$852 \mathrm{CPE}$ kinetics and complete CPE in $32 \mathrm{~h}$ after applying virus alone to Vero cells. Fifty (50) $\mu \mathrm{L}$ of

853 cell culture medium (DMEM supplemented with 2\% FBS) was added to each well of a 96-well

854 E-plate using a ViaFlo384 liquid handler (Integra Biosciences) to obtain background reading.

855 Eighteen thousand $(18,000)$ Vero cells in $50 \mu \mathrm{L}$ of cell culture medium were seeded per each

856 well, and the plate was placed on the analyzer. Measurements were taken automatically every 15

$857 \mathrm{~min}$, and the sensograms were visualized using RTCA software version 2.1.0 (ACEA

858 Biosciences Inc). VSV/EBOV GP ( 0.1 MOI, 2,000 PFU per well), or VSV/BDBV GP (0.04

859 MOI, 800 PFU per well) or VSV/SUDV GP (0.01 MOI, 240 PFU per well) were mixed 1:1

860 with respective dilution of mAb in triplicate a total volume of $100 \mu \mathrm{L}$ using DMEM

861 supplemented with $2 \% \mathrm{FBS}$ as a diluent and incubated for $1 \mathrm{~h}$ at $37^{\circ} \mathrm{C}$ in $5 \% \mathrm{CO}_{2}$. At 16 to $18 \mathrm{~h}$

862 after seeding the cells, the virus-mAb mixtures were added to the cells in 96-well E-plates.

863 Triplicate wells containing virus only (maximal CPE in the absence of mAb) and wells

864 containing only Vero cells in medium (no-CPE wells) were included as controls. Plates were

865 measured continuously (every $15 \mathrm{~min}$ ) for $48 \mathrm{~h}$ to assess virus neutralization. Normalized

866 cellular index $(\mathrm{CI})$ values at the endpoint (42 $\mathrm{h}$ after incubation with the virus) were determined

867 using the RTCA software version 2.1.0 (ACEA Biosciences Inc.). Results were expressed as

868 percent neutralization in the presence of a particular $\mathrm{mAb}$ relative to no-CPE control wells minus

869 CI values from control wells with maximum CPE. RTCA IC 50 values were determined by

870 nonlinear regression analysis using Prism software.

Measurement of synergistic virus neutralization by a combination of antibodies

873 We used RTCA assay to assess neutralizing activity from a pairwise combinatorial matrix of two

874 antibodies in the mixture. Serially-diluted rEBOV-442 (2-fold dilutions) was titrated into

875 serially-diluted rEBOV-515 (two-fold dilutions) and incubated with rVSV/EBOV GP,

$876 \mathrm{rVSV} / \mathrm{BDBV}$ GP, or rVSV/SUDV GP viruses for $1 \mathrm{~h}$ at $37^{\circ} \mathrm{C}$. Virus-antibody mixtures were

877 applied to Vero cells grown in 96-well E-plates in duplicates for each virus and using separate

878 plates for each pairwise combinatorial matrix. Triplicate wells containing virus only (maximal 
$879 \mathrm{CPE}$ in the absence of $\mathrm{mAb}$ ) and wells containing only Vero cells in medium (no CPE wells) were included as controls. Plates were measured continuously (every 15 minutes) for $48 \mathrm{~h}$ to assess virus neutralization. Normalized cellular index $(\mathrm{CI})$ values at the endpoint $(42 \mathrm{~h}$ after incubation with the virus) were determined using the RTCA software version 2.1.0 (ACEA Biosciences Inc.). Results were expressed as percent neutralization in the presence of a particular $\mathrm{mAb}$ relative to control wells with no CPE minus CI values from control wells with maximum CPE. Synergy distribution maps were generated from the dose-response binding matrix using a web application, SynergyFinder 2.0, and data was analyzed using ZIP synergy scoring model (Ianevski et al., 2020).

\section{Rapid fluorometric antibody-mediated cytotoxicity assay (RFADCC)}

Antibody-dependent cell-mediated cytotoxicity activity of EBOV GP-reactive IgG was quantified with an EBOV-adapted modification of the RFADCC assay (Domi et al., 2018; Orlandi et al., 2016). Briefly, a target cell line was made by transfecting 293F cells with a full-length DNA expressing GP from the EBOV-Kikwit isolate followed by transfecting with two separate DNA constructs expressing eGFP and the chimeric CCR5-SNAP tag protein. The new cell line, designated EBOV GPkik-293FS eGFP CCR5-SNAP, expresses EBOV-Kikwit GP on the plasma membrane, eGFP in the cytoplasm and the SNAP-tag CCR5, which can be specifically labeled with SNAP-Surface AF647 (NEB), on the cell surface (Domi et al., 2018). The unrelated human mAb DENV 2D22 and the Fc effector function disabled mAb rEBOV-515 LALA-PG were used as negative controls for the assay background. The ADCC activity was quantified by incubating three-fold serial dilutions of mAbs with EBOV GPkik-293FS eGFP CCR5-SNAP target cells for $15 \mathrm{~min}$ at ambient temperature and then adding human PBMC as effector cells for $2 \mathrm{hrs}$ at $37^{\circ} \mathrm{C}$, after which cells were washed once with PBS, fixed with 2\% PFA, stained and analyzed using an iQue Screener Plus flow cytometer (Intellicyt Corp.). Data analysis was performed with ForeCyt (Intellicyt Corp.) software. The percentage cytotoxicity of the mAb was determined as the number of target cells losing eGFP signal (by virtue of ADCC) but retaining the surface expression of CCR5-SNAP.

908 The assay was performed as we described previously (Gilchuk et al., 2018a). Briefly, Jurkat- 
910 temperature, then incubated with thermolysin (Promega) diluted in DPBS to $1 \mathrm{mg} / \mathrm{mL}$ for $20 \mathrm{~min}$

911 at $37^{\circ} \mathrm{C}$. The reaction was stopped by addition of the incubation buffer containing DPBS, $2 \%$

912 heat-inactivated FBS and 2 mM EDTA (pH 8.0). Washed cells were incubated with $5 \mu \mathrm{g} / \mathrm{mL}$ of

913 Alexa Fluor 647-labeled EBOV GP RBD-reactive mAb MR78 (Bornholdt et al., 2016) at $4^{\circ} \mathrm{C}$

914 for $60 \mathrm{~min}$. Stained cells were washed, fixed, and analyzed by flow cytometry using Intellicyt

915 iQue. Cells were gated for the viable population, and median fluorescence intensity from Alexa

916 Fluor 647 was determined. Background staining was determined from binding of the labeled

917 mAb MR78 to Jurkat-EBOV GP (uncleaved) cells. Results are expressed as the percent of RBS

918 exposure inhibition in the presence of tested $\mathrm{mAb}$ relative to controls for minimal binding of

919 labeled MR78 mAb-only to intact (uncleaved) Jurkat EBOV-GP, and maximal binding of

920 labeled MR78 mAb-only to cleaved Jurkat-EBOV GP.

\section{Mouse challenge}

923 Groups of mice ( $n=5$ per group) were inoculated with 1,000 PFU of the EBOV-MA by the 924 intraperitoneal (i.p.) route. Mice were treated i.p. with indicated doses of individual mAbs on 1 day 925 after virus inoculation (dpi). Human mAb DENV 2D22 served as a control. Mice were monitored 926 twice daily from 0 to 14 dpi for illness, survival, and weight loss, followed by once daily monitoring 927 from 15 dpi to the end of the study at $28 \mathrm{dpi}$. The extent of disease was scored using the following 928 parameters: score 1 - healthy; score 2 - ruffled fur and hunched posture; score 3 - a score of 2 plus 929 one additional clinical sign such as orbital tightening and/or $>15 \%$ weight loss; score 4 - a score of 3 930 plus one additional clinical sign such as reluctance to move when stimulated, or any neurologic signs 931 (seizures, tremors, head tilt, paralysis, etc.), or $>20 \%$ weight loss. Animals reaching a score of 4 932 were euthanized as per the IACUC-approved protocol. All mice were euthanized on day 28 after 933 EBOV challenge.

\section{NHP challenge}

936 Twelve healthy adult rhesus macaques (Macaca mulatta) of Chinese origin and six healthy adult 937 cynomolgus monkeys (Macaca fascicularis) were studied. Animals were assigned to three groups of 938 five animals per treatment group and a control untreated animal. Animals were randomized by 939 random number assignment (with Microsoft Excel) into a treatment group and a control animal. 940 After intramuscular challenge with a lethal target dose of 1,000 plaque-forming units (PFU) of 
$941 \mathrm{EBOV} / \mathrm{Kikwit}, \mathrm{BDBV} / \mathrm{Uganda}$, or SUDV/Gulu, each of the NHPs of the treatment group received

942 intravenously two $30 \mathrm{mg} / \mathrm{kg}$ doses of the cocktail (a 2:1 mixture of rEBOV-515 LALA-PG and

943 rEBOV-442 IgG1) spaced 3 days apart (days 3 and 6 after EBOV/Kikwit, days 6 and 9 after

944 BDBV/Uganda, or days 4 and 7 after SUDV SUDV/Gulu inoculation). The back-titer of the EBOV,

945 BDBV, and SUDV inoculum identified 963, 1113, and 988 PFU as the actual inoculation dose for

946 the respective virus. Historical untreated controls for EBOV challenge cohort included fourteen

947 untreated animals from separate studies including 11 animals, as we reported previously (Gilchuk et

948 al., 2020b), which were challenged with the same target dose of EBOV/Kikwit and by the same

949 route. Historical untreated controls for SUDV/Gulu challenge cohort included five untreated animals

950 from previous study (Thi et al., 2016) and four untreated animals from two other studies (Geisbert

951 and Cross, unpublished) that were challenged with the same target dose of BDBV and by the same

952 route. Historical untreated controls for BDBV challenge cohort included three untreated animals

953 from a previous study (Bornholdt et al., 2019) and seventeen untreated animals from the other

954 studies (Geisbert and Cross, unpublished) that were challenged with the same target dose of

$955 \mathrm{BDBV} /$ Uganda and by the same route. All animals were given physical exams, and blood was

956 collected at the time of inoculation and at indicated times after virus inoculation. In addition, all

957 animals were monitored daily and scored for disease progression with an internal filovirus scoring

958 protocol approved by the UTMB Institutional Animal Care and Use Committee. The scoring

959 measured from baseline and included posture or activity level, attitude or behavior, food and water

960 intake, respiration, and disease manifestations such as visible rash, hemorrhage, ecchymosis, or

961 flushed skin. A score of $\geq 9$ indicated that an animal met criteria for euthanasia. These studies were

962 not blinded, and all animals were included in analysis.

\section{Measurement of virus load in NHP blood and tissues}

965 Titration of virus in plasma samples and 10\% tissue homogenates $(\mathrm{w} / \mathrm{v})$ was performed by

966 plaque assay in Vero-E6 cell culture monolayers. Briefly, serial 10-fold dilutions of the samples

967 were applied to Vero-E6 cell monolayers in duplicate wells $(200 \mu \mathrm{L})$; the limit of detection was

$96825 \mathrm{PFU} / \mathrm{mL}$ for plasma and $250 \mathrm{PFU} /$ gram for tissue. For qRT-PCR analysis, RNA was isolated

969 from whole blood or tissue using the Viral RNA Mini-kit (Qiagen) using $100 \mu \mathrm{L}$ of blood or 100

$970 \mathrm{mg}$ of tissue into $600 \mu \mathrm{L}$ of buffer AVL. Primers (probes) targeting the VP30 gene of EBOV

971 probe sequence of 6-carboxyflourescein (6FAM)-5' CCG TCA ATC AAG GAG CGC CTC 3'-6 
972 carboxytetramethylrhodamine (TAMRA) (Thermo Fisher Scientific), the VP35 intergenic

973 region of BDBV probe sequence of 6FAM-5' CGCAACCTCCACAGTCGCCT 3'-TAMRA, and

974 the L gene of SUDV probe sequence of 6FAM-5' CAT CCA ATC AAA GAC ATT GCG A 3'-

975 TAMRA were used for qRT-PCR. EBOV RNA was detected using the CFX96 detection system

976 (BioRad Laboratories) in One-step probe qRT-PCR kits (Qiagen) with the following cycle

977 conditions: $50{ }^{\circ} \mathrm{C}$ for $10 \mathrm{~min}, 95^{\circ} \mathrm{C}$ for $10 \mathrm{~s}$, and 40 cycles of $95^{\circ} \mathrm{C}$ for $10 \mathrm{~s}$ and $57^{\circ} \mathrm{C}$ for $30 \mathrm{~s}$

978 for EBOV and BDBV and $50{ }^{\circ} \mathrm{C}$ for $10 \mathrm{~min}, 95^{\circ} \mathrm{C}$ for $10 \mathrm{~s}$, and 40 cycles of $95^{\circ} \mathrm{C}$ for $10 \mathrm{~s}$ and

$97959^{\circ} \mathrm{C}$ for $30 \mathrm{~s}$ for SUDV. Threshold cycle (CT) values representing EBOV, BDBV and SUDV

980 genomes were analyzed with CFX Manager Software, and data are depicted as genome

equivalents (GEq); the limit of detection was $3.7 \log _{10} \mathrm{GEq} / \mathrm{mL}$ for blood and $3.7 \log _{10} \mathrm{GEq} / \mathrm{g}$ for

982 the tissues.

983

\section{NHP serum biochemistry}

985 Serum samples collected from NHPs were tested for concentrations of albumin, amylase, alanine

986 aminotransferase, aspartate aminotransferase, alkaline phosphatase, gamma-glutamyltransferase,

987 glucose, blood urea nitrogen, creatinine, total protein, and C-reactive protein by using a Piccolo

988 point-of-care analyzer and Biochemistry Panel Plus analyzer discs (Abaxis).

\section{Sample preparation for cryogenic electron microscopy}

992 Fab, rEBOV-442 Fab, and rADI-16061 Fab at $4^{\circ} \mathrm{C}$. The complexes were then purified by SEC

993 using an S200I column equilibrated in 1X TBS and concentrated to $5 \mathrm{mg} / \mathrm{mL}$ using a $100-\mathrm{kDa}$

994 concentrator (Amicon Ultra, Millipore). Immediately prior to freezing, $0.06 \mathrm{mM}$ of n-Dodecyl $\beta$ -

995 D-maltoside (Anatrace) was added to $3 \mu \mathrm{L}$ of the complex. Vitrification was performed with a

996 Vitrobot (Thermo Fisher Scientific) equilibrated to $4^{\circ} \mathrm{C}$ and $100 \%$ humidity. Cryo-EM grids

997 were plasma cleaned for 5 s using a mixture of Ar/O2 (Gatan Solarus 950 Plasma system)

998 followed by blotting on both sides of the grid with filter paper (Whattman No. 1). See Table S7

999 for additional details. Note that ADI-16061 Fab was added to assist in angular sampling and 1000 orientations of the complexes in ice as we described previously (Gilchuk et al., 2020b). 
1003 Cryo-EM data were collected according to Table S1. Micrographs were aligned and doseweighted using MotionCor2 (Zheng et al., 2017). CTF estimation was completed using GCTF (Zheng et al., 2017). Particle picking and initial 2D classification were initially performed using

1006 CryoSPARC 2.0 (Punjani et al., 2017) to clean up particle stacks and exclude any complexes that 1007 were degrading. Particle picks were then imported into Relion 3.1 (Zivanov et al., 2018) for 3D

1008 classification and refinement using C3 symmetry and a tight mask around the GP/rEBOV-515 Fab/rEBOV-442 Fab complex. CTF refinement was then performed by either Relion or Cryosparc to increase map quality and resolution. There was no electron density for ADI-16061

1011 Fab.

1012

\section{Cryogenic electron microscopy model building and refinement}

1014 Homology models of Fab were first generated using SWISS-MODEL (Biasini et al., 2014). A model of EBOV GP (PDB: 5JQ3) was then added to generate a starting model used for refinement. The starting model was fit into the cryo-EM map using UCSF Chimera (Pettersen et al., 2004) and refined initially using Phenix real-space refinement (Liebschner et al., 2019). The refined model was then used as a starting model for relaxed refinement in Rosetta (DiMaio et al., 2015). The top five models then were evaluated for fit in EM density and adjusted manually using Coot (Emsley et al., 2010) to maximize fit. Finally, Man9 glycans were fit into glycan densities, trimmed and then a final refinement was performed in Rosetta. The final structures were evaluated using EMRinger (Barad et al., 2015) and Molprobity from Phenix. Glycans were validated using Privateer (Agirre et al., 2015) and PDBcare (Lutteke and von der Lieth, 2004). All map and model images were generated in UCSF Chimera (Pettersen et al., 2004). Antibody contacts were analyzed using LigPlot (Laskowski and Swindells, 2011), Arpeggio (Jubb et al., 2017) and UCSF Chimera (Pettersen et al., 2004).

1029 The descriptive statistics mean \pm SEM or mean \pm SD were determined for continuous variables 1030 as noted. Survival curves were estimated using the Kaplan-Meier method and overall difference 1031 in survival between the groups in mouse studies was estimated using two-sided log rank test 1032 (Mantel-Cox) with subjects right censored, if they survived until the end of the study. In NHP 1033 studies, survival curves were estimated using the Kaplan-Meier method, and the proportion 
1034 surviving at day 28 after virus inoculation was compared using a 2-sided exact unconditional test

1035 of homogeneity. Curves for antibody binding were fitted after log transformation of antibody

1036 concentrations using a four-parameter log-logistic (4PL) analysis. In neutralization assays and

1037 GP cleavage inhibition assays, IC $_{50}$ values were calculated after log transformation of antibody

1038 concentrations using a four-parameter log-logistic (4PL) analysis. Synergy distribution maps

1039 were generated from the dose-response binding matrix using an open-source software

1040 SynergyFinder 2.0: visual analytics of multi-drug combination synergies

1041 (https://synergyfinder.fimm.fi), and data was analyzed using ZIP synergy scoring model

1042 (Ianevski et al., 2020). Technical and biological replicates are indicated in the figure legends.

1043 Statistical analyses were performed using Prism v8.4.3 (GraphPad).

\section{DATA AND CODE AVAILABILITY}

1046 The EBOV GP $\triangle$ Muc $\Delta$ TM (Makona)-rEBOV-515-rEBOV-442 Fab cryo-EM structure has

1047 been deposited in the PDB with accession code 7M8L. The accession number for cryo-EM

1048 reconstructions reported in this paper have been deposited to the Electron Microscopy Data Bank

1049 under accession EMDB code EMD-23719 (see Key Resources Table for details). All data needed

1050 to evaluate the conclusions in the paper are present in the paper or the Supplemental Information;

1051 source data for each of the display items is provided in Key Resources Table. 


\section{References}

1064 Agirre, J., Iglesias-Fernandez, J., Rovira, C., Davies, G.J., Wilson, K.S., and Cowtan, K.D. 1065 (2015). Privateer: software for the conformational validation of carbohydrate structures. Nat. 1066 Struct. Mol. Biol. 22, 833-834.

1067

1068 1069 1070 1071 1072 1073 1074 1075 1076 1077 1078 1079 1080 1081 1082 1083 1084 1085 1086 1087 1088 1089

1090 1091 1092 1093 1094 1095 1096 1097 1098 1099 1100 1101 1102 1103 1104 1105 1106 1107 1108

Barad, B.A., Echols, N., Wang, R.Y., Cheng, Y., DiMaio, F., Adams, P.D., and Fraser, J.S. (2015). EMRinger: side chain-directed model and map validation for 3D cryo-electron microscopy. Nat. Methods 12, 943-946.

Baum, A., Fulton, B.O., Wloga, E., Copin, R., Pascal, K.E., Russo, V., Giordano, S., Lanza, K., Negron, N., Ni, M., et al. (2020). Antibody cocktail to SARS-CoV-2 spike protein prevents rapid mutational escape seen with individual antibodies. Science 369, 1014-1018.

Bennett, R.S., Huzella, L.M., Jahrling, P.B., Bollinger, L., Olinger, G.G., Jr., and Hensley, L.E. (2017). Nonhuman primate models of Ebola virus disease. Curr. Top. Microbiol. Immunol 411, 171-193.

Biasini, M., Bienert, S., Waterhouse, A., Arnold, K., Studer, G., Schmidt, T., Kiefer, F., Gallo Cassarino, T., Bertoni, M., Bordoli, L., et al. (2014). SWISS-MODEL: modelling protein tertiary and quaternary structure using evolutionary information. Nucleic Acids Res. 42, W252-258.

Bornholdt, Z.A., Herbert, A.S., Mire, C.E., He, S., Cross, R.W., Wec, A.Z., Abelson, D.M., Geisbert, J.B., James, R.M., Rahim, M.N., et al. (2019). A two-antibody pan-ebolavirus cocktail confers broad therapeutic protection in ferrets and nonhuman primates. Cell Host Microbe 25, 49-58 e45.

Bornholdt, Z.A., Ndungo, E., Fusco, M.L., Bale, S., Flyak, A.I., Crowe, J.E., Jr., Chandran, K., and Saphire, E.O. (2016). Host-primed Ebola virus GP exposes a hydrophobic NPC1 receptorbinding pocket, revealing a target for broadly neutralizing antibodies. mBio 7, e02154-02115.

Bray, M., Davis, K., Geisbert, T., Schmaljohn, C., and Huggins, J. (1998). A mouse model for evaluation of prophylaxis and therapy of Ebola hemorrhagic fever. J. Infect. Dis. 178, 651-661.

Brown, J.F., Dye, J.M., Tozay, S., Jeh-Mulbah, G., Wohl, D.A., Fischer, W.A., 2nd, Cunningham, C.K., Rowe, K., Zacharias, P., van Hasselt, J., et al. (2018). Anti-Ebola virus antibody levels in convalescent plasma and viral load after plasma infusion in patients with Ebola virus disease. J. Infect. Dis. 218, 555-562.

Carette, J.E., Raaben, M., Wong, A.C., Herbert, A.S., Obernosterer, G., Mulherkar, N., Kuehne, A.I., Kranzusch, P.J., Griffin, A.M., Ruthel, G., et al. (2011). Ebola virus entry requires the cholesterol transporter Niemann-Pick C1. Nature 477, 340-343.

Chandran, K., Sullivan, N.J., Felbor, U., Whelan, S.P., and Cunningham, J.M. (2005).

Endosomal proteolysis of the Ebola virus glycoprotein is necessary for infection. Science 308, 1643-1645. 
Chng, J., Wang, T., Nian, R., Lau, A., Hoi, K.M., Ho, S.C., Gagnon, P., Bi, X., and Yang, Y. (2015). Cleavage efficient 2A peptides for high level monoclonal antibody expression in $\mathrm{CHO}$ cells. mAbs 7, 403-412.

Corti, D., Misasi, J., Mulangu, S., Stanley, D.A., Kanekiyo, M., Wollen, S., Ploquin, A., Doriavirus infection by a potently neutralizing antibody. Science $351,1339-1342$.

Cross, R.W., Mire, C.E., Borisevich, V., Geisbert, J.B., Fenton, K.A., and Geisbert, T.W. (2016). The Domestic Ferret (Mustela putorius furo) as a lethal infection model for 3 species of ebolavirus. J. Infect. Dis. 214, 565-569.

Davis, C.W., Jackson, K.J.L., McElroy, A.K., Halfmann, P., Huang, J., Chennareddy, C., Piper, A.E., Leung, Y., Albarino, C.G., Crozier, I., et al. (2019). Longitudinal analysis of the human B cell response to Ebola virus infection. Cell 177, 1566-1582 e1517.

Diallo, B., Sissoko, D., Loman, N.J., Bah, H.A., Bah, H., Worrell, M.C., Conde, L.S., Sacko, R., survivor with virus persistence in seminal fluid for more than 500 days. Clin. Infect. Dis. 63, 1353-1356.

DiMaio, F., Song, Y., Li, X., Brunner, M.J., Xu, C., Conticello, V., Egelman, E., Marlovits, T., data with density-guided iterative local refinement. Nat. Methods 12, 361-365.

Domi, A., Feldmann, F., Basu, R., McCurley, N., Shifflett, K., Emanuel, J., Hellerstein, M.S., expressing Ebola virus like particles protects nonhuman primates from lethal Ebola virus challenge. Sci. Rep. 8, 864.

Emsley, P., Lohkamp, B., Scott, W.G., and Cowtan, K. (2010). Features and development of Coot. Acta Crystallogr. D Biol. Crystallogr. 66, 486-501.

FDA (2020a). FDA Approves First Treatment for Ebola Virus. wwwfdagov/news-events/pressannouncements/fda-approves-first-treatment-ebola-virus (accessed 21 March 2021).

FDA (2020b). FDA Approves Treatment for Ebola Virus. wwwfdagov/drugs/drug-safety-andavailability/fda-approves-treatment-ebola-virus (accessed 21 March 2021).

Feldmann, H., Sprecher, A., and Geisbert, T.W. (2020). Ebola. New Engl. J. Med. 382, 18321842.

Fibriansah, G., Ibarra, K.D., Ng, T.S., Smith, S.A., Tan, J.L., Lim, X.N., Ooi, J.S.G., Kostyuchenko, V.A., Wang, J.Q., de Silva, A.M., et al. (2015). Cryo-EM structure of an antibody that neutralizes dengue virus type 2 by locking E protein dimers. Science 349, 88-91. 
Garbutt, M., Liebscher, R., Wahl-Jensen, V., Jones, S., Moller, P., Wagner, R., Volchkov, V., Klenk, H.D., Feldmann, H., and Stroher, U. (2004). Properties of replication-competent vesicular stomatitis virus vectors expressing glycoproteins of filoviruses and arenaviruses. J. Virol. 78, 5458-5465.

Gaudinski, M.R., Coates, E.E., Novik, L., Widge, A., Houser, K.V., Burch, E., Holman, L.A., Gordon, I.J., Chen, G.L., Carter, C., et al. (2019). Safety, tolerability, pharmacokinetics, and immunogenicity of the therapeutic monoclonal antibody mAb114 targeting Ebola virus glycoprotein (VRC 608): an open-label phase 1 study. Lancet 393, 889-898.

Geisbert, T.W., Daddario-DiCaprio, K.M., Williams, K.J., Geisbert, J.B., Leung, A., Feldmann, F., Hensley, L.E., Feldmann, H., and Jones, S.M. (2008). Recombinant vesicular stomatitis virus vector mediates postexposure protection against Sudan Ebola hemorrhagic fever in nonhuman primates. J. Virol. 82, 5664-5668.

Geisbert, T.W., Strong, J.E., and Feldmann, H. (2015). Considerations in the use of nonhuman primate models of Ebola virus and Marburg virus infection. J. Infect. Dis. 212, S91-S97.

Gilchuk, P., Bombardi, R.G., Erasmus, J.H., Tan, Q., Nargi, R., Soto, C., Abbink, P., Suscovich, T.J., Durnell, L.A., Khandhar, A., et al. (2020a). Integrated pipeline for the accelerated discovery of antiviral antibody therapeutics. Nat. Biomed. Eng. 4, 1030-1043.

Gilchuk, P., Kuzmina, N., Ilinykh, P.A., Huang, K., Gunn, B.M., Bryan, A., Davidson, E., Doranz, B.J., Turner, H.L., Fusco, M.L., et al. (2018a). Multifunctional pan-ebolavirus antibody recognizes a site of broad vulnerability on the Ebolavirus glycoprotein. Immunity 49, 363-374 e310.

Gilchuk, P., Mire, C.E., Geisbert, J.B., Agans, K.N., Deer, D.J., Cross, R.W., Slaughter, J.C., Flyak, A.I., Mani, J., Pauly, M.H., et al. (2018b). Efficacy of human monoclonal antibody monotherapy against Bundibugyo virus infection in nonhuman primates. J. Infect. Dis. 218, S565-S573.

Gilchuk, P., Murin, C.D., Milligan, J.C., Cross, R.W., Mire, C.E., Ilinykh, P.A., Huang, K., Kuzmina, N., Altman, P.X., Hui, S., et al. (2020b). Analysis of a therapeutic antibody cocktail reveals determinants for cooperative and broad ebolavirus neutralization. Immunity 52, 388-403 e312.

Goldstein, T., Anthony, S.J., Gbakima, A., Bird, B., Bangura, J., Tremeau-Bravard, A., Belaganahalli, M., Wells, H., Dhanota, J., Liang, E., et al. (2019). The discovery of a new Ebolavirus, Bombali virus, adds further support for bats as hosts of ebolaviruses. Int. J. Infect. Dis. 79, 4-5. the SARS-CoV-2 spike receptor-binding domain that escape antibody recognition. Cell Host Microbe 29, 44-57 e9. 
Herbert, A.S., Froude, J.W., Ortiz, R.A., Kuehne, A.I., Dorosky, D.E., Bakken, R.R., Zak, S.E., Josleyn, N.M., Musiychuk, K., Jones, R.M., et al. (2020). Development of an antibody cocktail for treatment of Sudan virus infection. Pros. Natl. Acad. Sci. U.S.A. 117, 3768-3778.

Ianevski, A., Giri, A.K., and Aittokallio, T. (2020). SynergyFinder 2.0: visual analytics of multidrug combination synergies. Nucleic Acids Res. 48, W488-W493.

Iversen, P.L., Kane, C.D., Zeng, X.K., Panchal, R.G., Warren, T.K., Radoshitzky, S.R., Kuhn, J.H., Mudhasani, R.R., Cooper, C.L., Shurtleff, A.C., et al. (2020). Recent successes in therapeutics for Ebola virus disease: no time for complacency. Lancet Infect. Dis. 20, E231E237.

Jubb, H.C., Higueruelo, A.P., Ochoa-Montano, B., Pitt, W.R., Ascher, D.B., and Blundell, T.L. (2017). Arpeggio: A web server for calculating and visualising interatomic interactions in protein structures. J. Mol. Biol. 429, 365-371.

King, L.B., Milligan, J.C., West, B.R., Schendel, S.L., and Ollmann Saphire, E. (2019). Achieving cross-reactivity with pan-ebolavirus antibodies. Curr. Opin. Virol. 34, 140-148.

King, L.B., West, B.R., Schendel, S.L., and Saphire, E.O. (2018). The structural basis for filovirus neutralization by monoclonal antibodies. Curr. Opin. Immunol. 53, 196-202.

Kugelman, J.R., Kugelman-Tonos, J., Ladner, J.T., Pettit, J., Keeton, C.M., Nagle, E.R., Garcia, K.Y., Froude, J.W., Kuehne, A.I., Kuhn, J.H., et al. (2015). Emergence of Ebola virus escape variants in infected nonhuman primates treated with the MB-003 antibody cocktail. Cell Rep. 12, 2111-2120.

Kuhn, J.H., Adachi, T., Adhikari, N.K.J., Arribas, J.R., Bah, I.E., Bausch, D.G., Bhadelia, N., Borchert, M., Brantsaeter, A.B., Brett-Major, D.M., et al. (2019). New filovirus disease classification and nomenclature. Nat. Rev. Microbiol. 17, 261-263.

Kuzmina, N.A., Younan, P., Gilchuk, P., Santos, R.I., Flyak, A.I., Ilinykh, P.A., Huang, K., Lubaki, N.M., Ramanathan, P., Crowe, J.E., Jr., et al. (2018). Antibody-dependent enhancement of Ebola virus infection by human antibodies isolated from survivors. Cell Rep. 24, 1802-1815 e1805.

Laskowski, R.A., and Swindells, M.B. (2011). LigPlot+: multiple ligand-protein interaction diagrams for drug discovery. J. Chem. Inf. Model. 51, 2778-2786. 
Lee, J.E., Fusco, M.L., Hessell, A.J., Oswald, W.B., Burton, D.R., and Saphire, E.O. (2008). Structure of the Ebola virus glycoprotein bound to an antibody from a human survivor. Nature 454, 177-182.

Lee, J.E., and Saphire, E.O. (2009). Neutralizing ebolavirus: structural insights into the envelope glycoprotein and antibodies targeted against it. Curr. Opin. Struc. Biol. 19, 408-417.

Levine, M.M. (2019). Monoclonal antibody therapy for Ebola virus disease. New Engl. J. Med. $381,2365-2366$.

Liebschner, D., Afonine, P.V., Baker, M.L., Bunkoczi, G., Chen, V.B., Croll, T.I., Hintze, B., Hung, L.W., Jain, S., McCoy, A.J., et al. (2019). Macromolecular structure determination using X-rays, neutrons and electrons: recent developments in Phenix. Acta Crystallogr. D Biol. Crystallogr. 75, 861-877.

Lutteke, T., and von der Lieth, C.W. (2004). pdb-care (PDB carbohydrate residue check): a program to support annotation of complex carbohydrate structures in PDB files. BMC Bioinformatics 5, 69.

Mbala-Kingebeni, P., Aziza, A., Di Paola, N., Wiley, M.R., Makiala-Mandanda, S., Caviness, K., Pratt, C.B., Ladner, J.T., Kugelman, J.R., Prieto, K., et al. (2019). Medical countermeasures during the 2018 Ebola virus disease outbreak in the North Kivu and Ituri Provinces of the Democratic Republic of the Congo: a rapid genomic assessment. Lancet Infect. Dis. 19, 648-657.

Mire, C.E., Geisbert, J.B., Marzi, A., Agans, K.N., Feldmann, H., and Geisbert, T.W. (2013). Vesicular stomatitis virus-based vaccines protect nonhuman primates against Bundibugyo ebolavirus. PLOS Neg1. Trop. Dis. 7, e2600.

Misasi, J., and Sullivan, N.J. (2021). Immunotherapeutic strategies to target vulnerabilities in the Ebolavirus glycoprotein. Immunity 54, 412-436.

Mulangu, S., Dodd, L.E., Davey, R.T., Jr., Tshiani Mbaya, O., Proschan, M., Mukadi, D., Lusakibanza Manzo, M., Nzolo, D., Tshomba Oloma, A., Ibanda, A., et al. (2019). A randomized, controlled trial of Ebola virus disease therapeutics. New Engl. J. Med. 381, 22932303.

Murin, C.D., Gilchuk, P., Alkutkar, T., Bruhn, J.F., Williamson, L.E., Copps, J., Ilinykh, P.A., Huang, K., Kuzmina, N., Bryan, A.L., et al. (2021). Convergence of a common solution to broad ebolavirus neutralization by glycan cap directed human antibodies. Cell Rep. (in press).

Orlandi, C., Flinko, R., and Lewis, G.K. (2016). A new cell line for high throughput HIVspecific antibody-dependent cellular cytotoxicity (ADCC) and cell-to-cell virus transmission studies. J. Immunol. Methods 433, 51-58.

Pascal, K.E., Dudgeon, D., Trefry, J.C., Anantpadma, M., Sakurai, Y., Murin, C.D., Turner, H.L., Fairhurst, J., Torres, M., Rafique, A., et al. (2018). Development of clinical-stage human 
monoclonal antibodies that treat advanced Ebola virus disease in nonhuman primates. J. Infect. Dis. 218, S612-S626.

Pettersen, E.F., Goddard, T.D., Huang, C.C., Couch, G.S., Greenblatt, D.M., Meng, E.C., and Ferrin, T.E. (2004). UCSF Chimera--a visualization system for exploratory research and analysis. J. Comput. Chem. 25, 1605-1612.

Punjani, A., Rubinstein, J.L., Fleet, D.J., and Brubaker, M.A. (2017). cryoSPARC: algorithms for rapid unsupervised cryo-EM structure determination. Nat. Methods 14, 290-296.

Qiu, X., Wong, G., Audet, J., Bello, A., Fernando, L., Alimonti, J.B., Fausther-Bovendo, H., Wei, H., Aviles, J., Hiatt, E., et al. (2014). Reversion of advanced Ebola virus disease in nonhuman primates with ZMapp. Nature 514, 47-53.

Saphire, E.O., Schendel, S.L., Fusco, M.L., Gangavarapu, K., Gunn, B.M., Wec, A.Z., Halfmann, P.J., Brannan, J.M., Herbert, A.S., Qiu, X., et al. (2018). Systematic analysis of monoclonal antibodies against Ebola virus GP defines features that contribute to protection. Cell 174, 938-952 e913.

Sivapalasingam, S., Kamal, M., Slim, R., Hosain, R., Shao, W., Stoltz, R., Yen, J., Pologe, L.G., Cao, Y., Partridge, M., et al. (2018). Safety, pharmacokinetics, and immunogenicity of a coformulated cocktail of three human monoclonal antibodies targeting Ebola virus glycoprotein in healthy adults: a randomised, first-in-human phase 1 study. Lancet Infect. Dis. 18, 884-893.

Starr, T.N., Greaney, A.J., Dingens, A.S., and Bloom, J.D. (2021). Complete map of SARSCoV-2 RBD mutations that escape the monoclonal antibody LY-CoV555 and its cocktail with LY-CoV016. BioRxiv [preprint]. doi: 10.1101/2021.02.17.431683.

Subtil, F., Delaunay, C., Keita, A.K., Sow, M.S., Toure, A., Leroy, S., Msellati, P., Magassouba, N., Baize, S., Raoul, H., et al. (2017). Dynamics of Ebola RNA persistence in semen: a report from the postebogui cohort in Guinea. Clin. Infect. Dis. 64, 1788-1790.

Thi, E.P., Lee, A.C., Geisbert, J.B., Ursic-Bedoya, R., Agans, K.N., Robbins, M., Deer, D.J., Fenton, K.A., Kondratowicz, A.S., MacLachlan, I., et al. (2016). Rescue of non-human primates from advanced Sudan ebolavirus infection with lipid encapsulated siRNA. Nat. Microbiol. 1, 16142.

Towner, J.S., Paragas, J., Dover, J.E., Gupta, M., Goldsmith, C.S., Huggins, J.W., and Nichol, S.T. (2005). Generation of eGFP expressing recombinant Zaire ebolavirus for analysis of early pathogenesis events and high-throughput antiviral drug screening. Virology 332, 20-27.

Towner, J.S., Sealy, T.K., Khristova, M.L., Albarino, C.G., Conlan, S., Reeder, S.A., Quan, P.L., Lipkin, W.I., Downing, R., Tappero, J.W., et al. (2008). Newly discovered ebola virus associated with hemorrhagic fever outbreak in Uganda. PLOS Pathog. 4, e1000212. 
Varkey, J.B., Shantha, J.G., Crozier, I., Kraft, C.S., Lyon, G.M., Mehta, A.K., Kumar, G., Smith, J.R., Kainulainen, M.H., Whitmer, S., et al. (2015). Persistence of Ebola virus in ocular fluid during convalescence. New Engl. J. Med. 372, 2423-2427.

virological.org (2021). Guinea 2021 EBOV outbreak. https://virologicalorg/t/guinea-2021-ebovoutbreak/643 (accessed 21 March 2021).

Wang, P., Nair, M.S., Liu, L., Iketani, S., Luo, Y., Guo, Y., Wang, M., Yu, J., Zhang, B., Kwong, P.D., et al. (2021). Antibody resistance of SARS-CoV-2 variants B.1.351 and B.1.1.7. Nature. doi.org/10.1038/s41586-021-03398-2

Wec, A.Z., Bornholdt, Z.A., He, S., Herbert, A.S., Goodwin, E., Wirchnianski, A.S., Gunn, B.M., Zhang, Z., Zhu, W., Liu, G., et al. (2019). Development of a human antibody cocktail that deploys multiple functions to confer pan-ebolavirus protection. Cell Host Microbe 25, 39-48 e35.

Wec, A.Z., Herbert, A.S., Murin, C.D., Nyakatura, E.K., Abelson, D.M., Fels, J.M., He, S., James, R.M., de La Vega, M.A., Zhu, W., et al. (2017). Antibodies from a human survivor define sites of vulnerability for broad protection against ebolaviruses. Cell 169, 878-890 e815.

West, B.R., Wec, A.Z., Moyer, C.L., Fusco, M.L., Ilinykh, P.A., Huang, K., Wirchnianski, A.S., James, R.M., Herbert, A.S., Hui, S., et al. (2019). Structural basis of broad ebolavirus neutralization by a human survivor antibody. Nat. Struct. Mol. Biol. 26, 204-212.

WHO (2021). Ebola virus disease. wwwwhoint/en/news-room/fact-sheets/detail/ebola-virusdisease (accessed 21 March 2021)

Yewdell, J.W., Webster, R.G., and Gerhard, W.U. (1979). Antigenic variation in three distinct determinants of an influenza type A haemagglutinin molecule. Nature 279, 246-248.

Zheng, S.Q., Palovcak, E., Armache, J.P., Verba, K.A., Cheng, Y., and Agard, D.A. (2017). MotionCor2: anisotropic correction of beam-induced motion for improved cryo-electron microscopy. Nat. Methods 14,331-332.

Zivanov, J., Nakane, T., Forsberg, B.O., Kimanius, D., Hagen, W.J., Lindahl, E., and Scheres, S.H. (2018). New tools for automated high-resolution cryo-EM structure determination in RELION-3. Elife 7. 
Figure 1

A

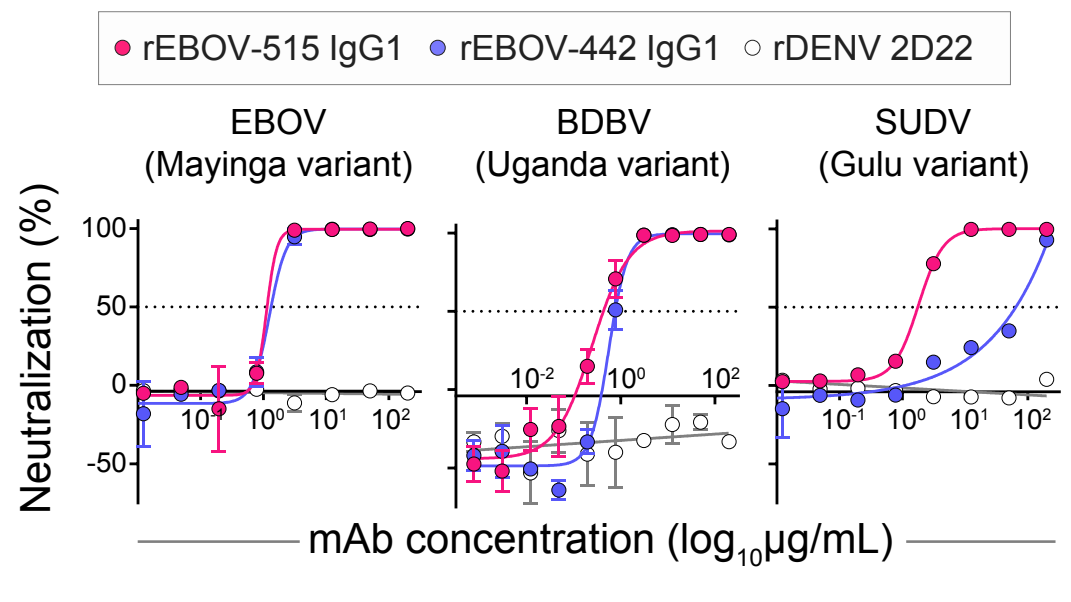

C

\begin{tabular}{|c|c|c|c|c|c|c|c|c|c|c|c|}
\hline \multirow{2}{*}{ mAb } & \multicolumn{5}{|c|}{$\begin{array}{l}\text { GP binding by ELISA } \\
\left(\mathrm{EC}_{50} ; \mathrm{ng} / \mathrm{mL}\right)\end{array}$} & \multicolumn{3}{|c|}{$\begin{array}{l}\text { Virus neutralization } \\
\left(\mathrm{IC}_{50} ; \mathrm{ng} / \mathrm{mL}\right)\end{array}$} & \multirow{2}{*}{$\begin{array}{l}\text { Fc region- } \\
\text { mediated } \\
\text { cytotoxicity } \\
\text { (relative) }\end{array}$} & \multirow{2}{*}{ Site on GP* } & \multirow{2}{*}{$\begin{array}{c}\% \text { protection } \\
\text { in mice } \\
(E B O V)^{*}\end{array}$} \\
\hline & EBOV & BDBV & SUDV & MARV & $\begin{array}{l}\text { EBOV } \\
\text { sGP }\end{array}$ & EBOV & BDBV & SUDV & & & \\
\hline rEBOV-442 lgG1 & 9 & 20 & 61 & $>$ & 2 & 1,241 & 762 & $\sim 64,000$ & High & Glycan cap & $80-100$ \\
\hline rEBOV-515 IgG1 & 47 & 91 & 263 & $>$ & $>$ & 1,117 & 435 & 1,808 & Low & Base & 100 \\
\hline
\end{tabular}

D

\begin{tabular}{|c|c|c|c|c|}
\hline Antibody & $\begin{array}{c}\text { Replicates with } \\
\text { escape / total } \\
\text { replicates (\%) }\end{array}$ & $\begin{array}{l}\text { Confirmed escape } \\
\text { at } 20 \mu \mathrm{g} / \mathrm{mL} \mathrm{mAb}\end{array}$ & $\begin{array}{c}\text { EBOV-442 escape } \\
\text { neutralization by } \\
20 \mu \mathrm{g} / \mathrm{mL} \text { mAb }\end{array}$ & $\begin{array}{l}\text { Mutations selected (number of } \\
\text { times of } 7 \text { sequenced escapes) }\end{array}$ \\
\hline rEBOV-442 & $60 / 60(100 \%)$ & Yes (all tested) & No & $\begin{array}{l}\text { L273P (7) })^{\star *} \text { F234V (2); G271E (1); K272Q } \\
\text { (1); I274V (1); K280E (1); V311A (2) }\end{array}$ \\
\hline rEBOV-515 & $0 / 60(0 \%)$ & Not applicable & Yes & Not applicable \\
\hline Cocktail (1:1) & $0 / 60(0 \%)$ & Not applicable & Yes & Not applicable \\
\hline
\end{tabular}


Figure 2

A
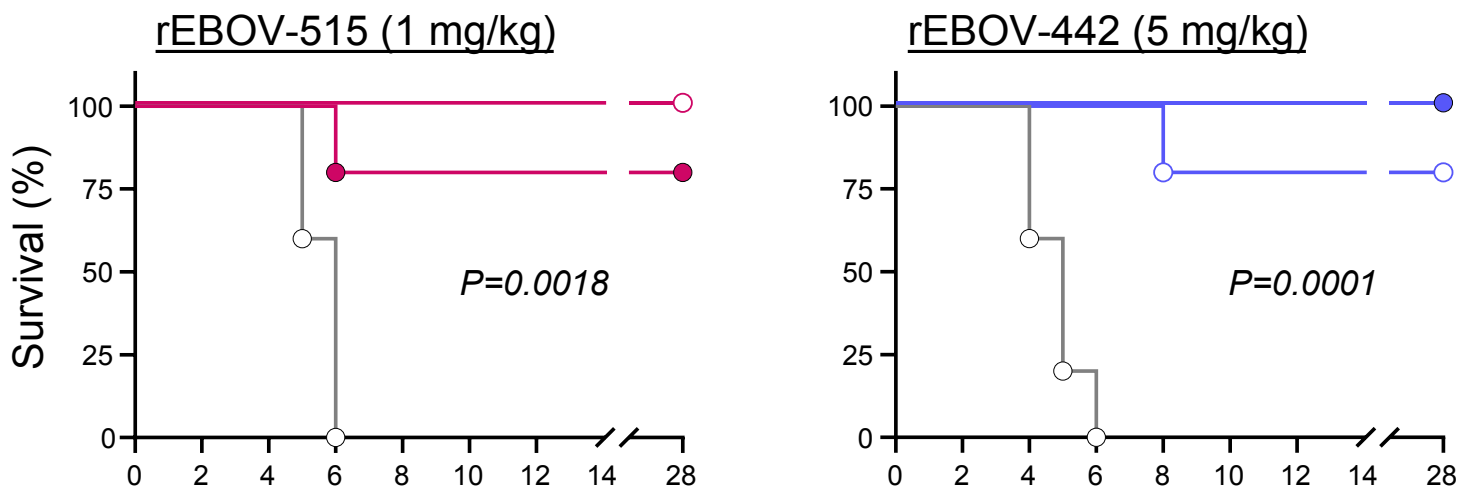

B
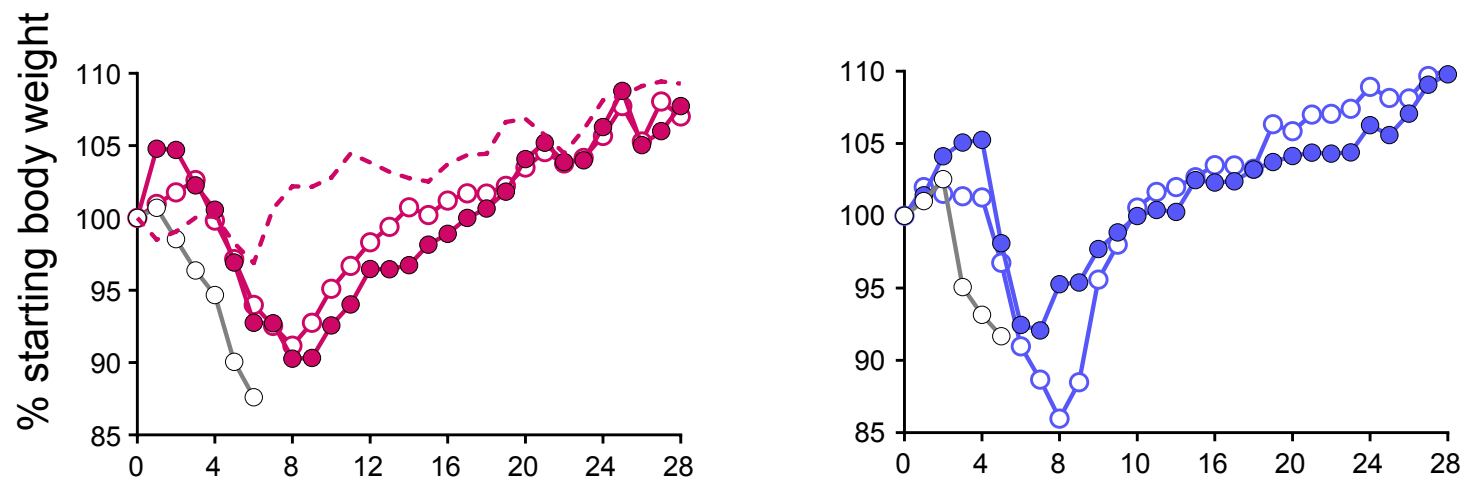

C
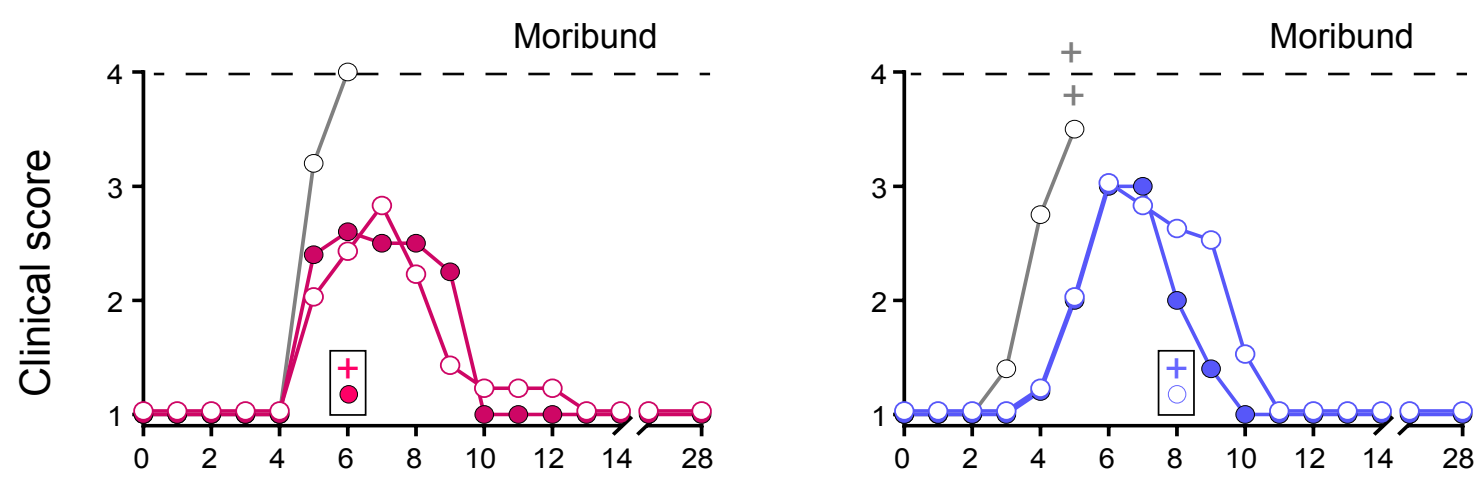

Days after challenge

- rEBOV-515 IgG1

rEBOV-515 LALA-PG

--- rEBOV-515 lgG1 (historical $5 \mathrm{mg} / \mathrm{kg}$ )

○ rDENV 2D22
- rEBOV-442 IgG1

rEBOV-442 LALA-PG

rDENV 2D22

All groups $n=5$ 
Figure 3

A

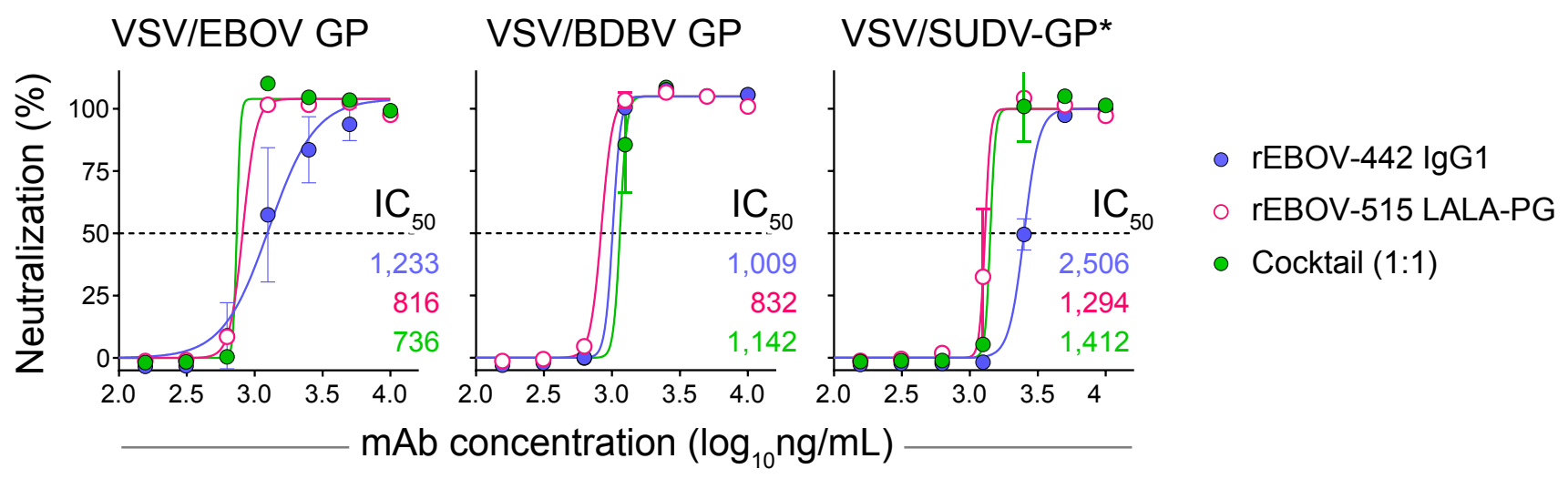

$\mathrm{B}$
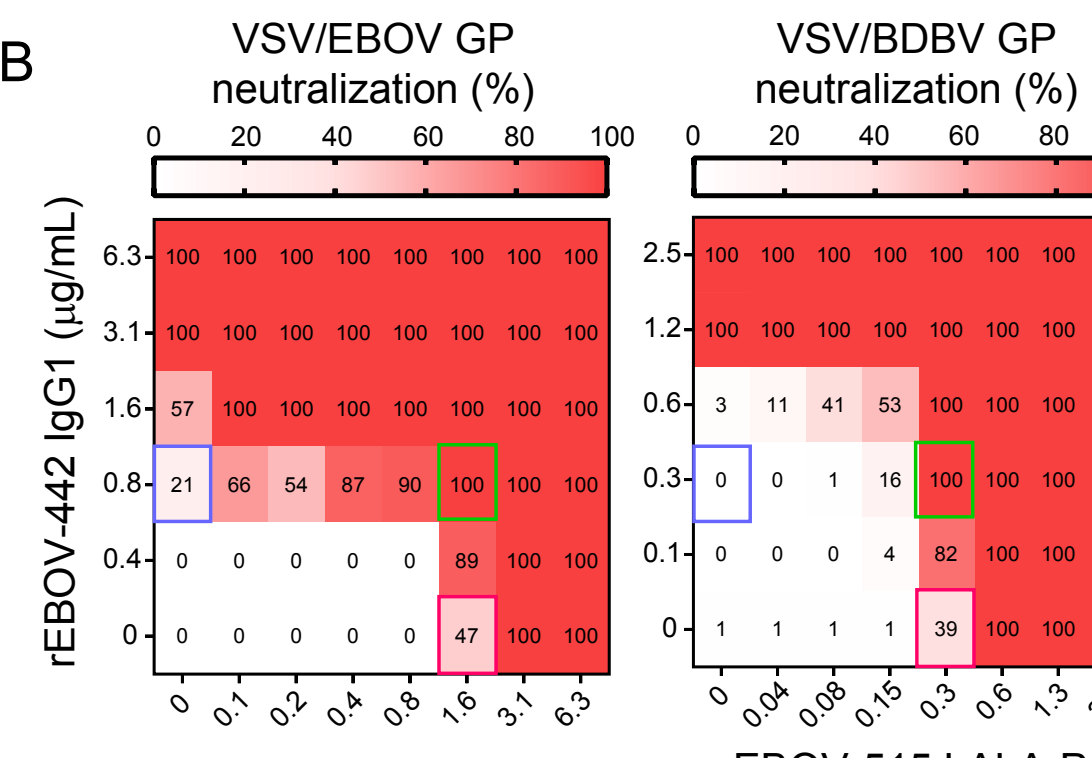

VSVISUDV GP neutralization (\%)
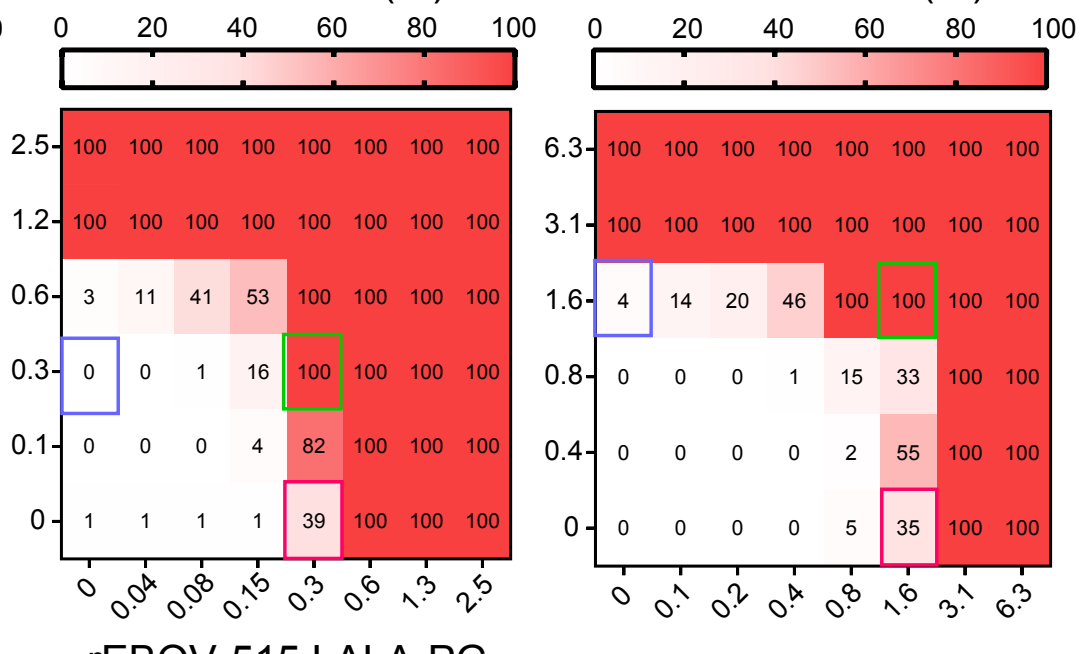

rEBOV-515 LALA-PG $(\mu \mathrm{g} / \mathrm{mL})$

C

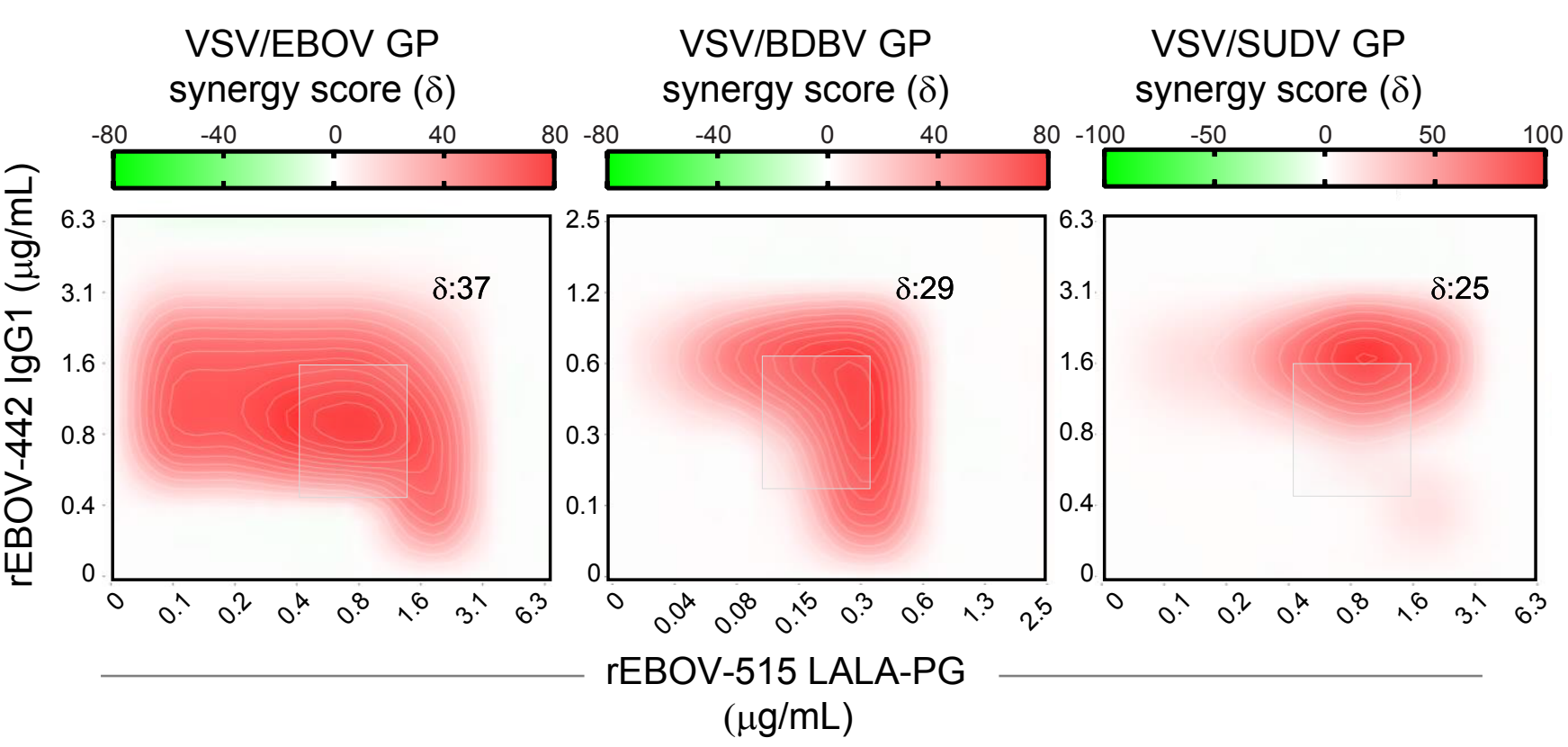


A

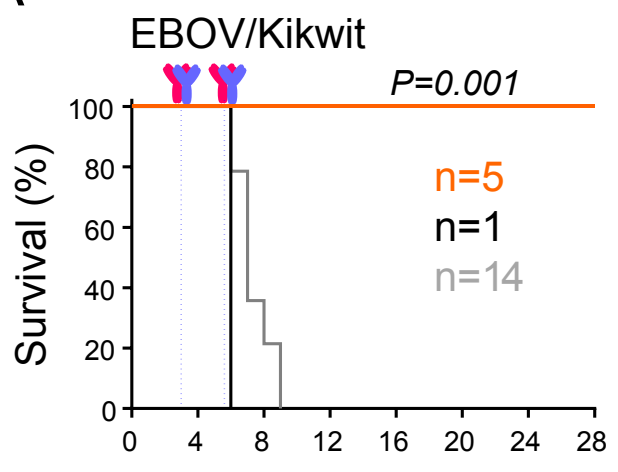

B

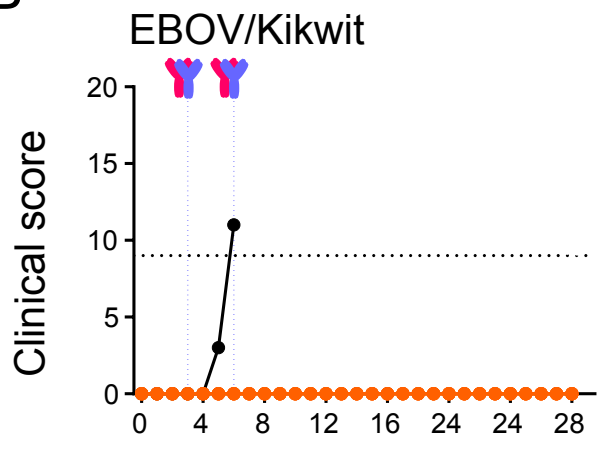

BDBV/Uganda

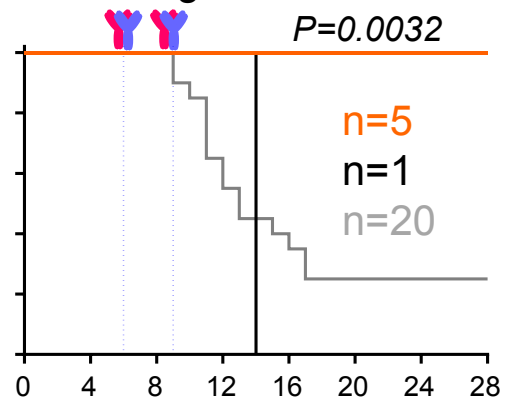

Days after challenge
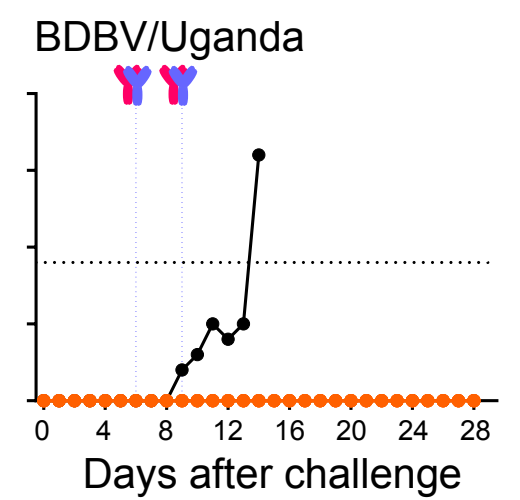

C

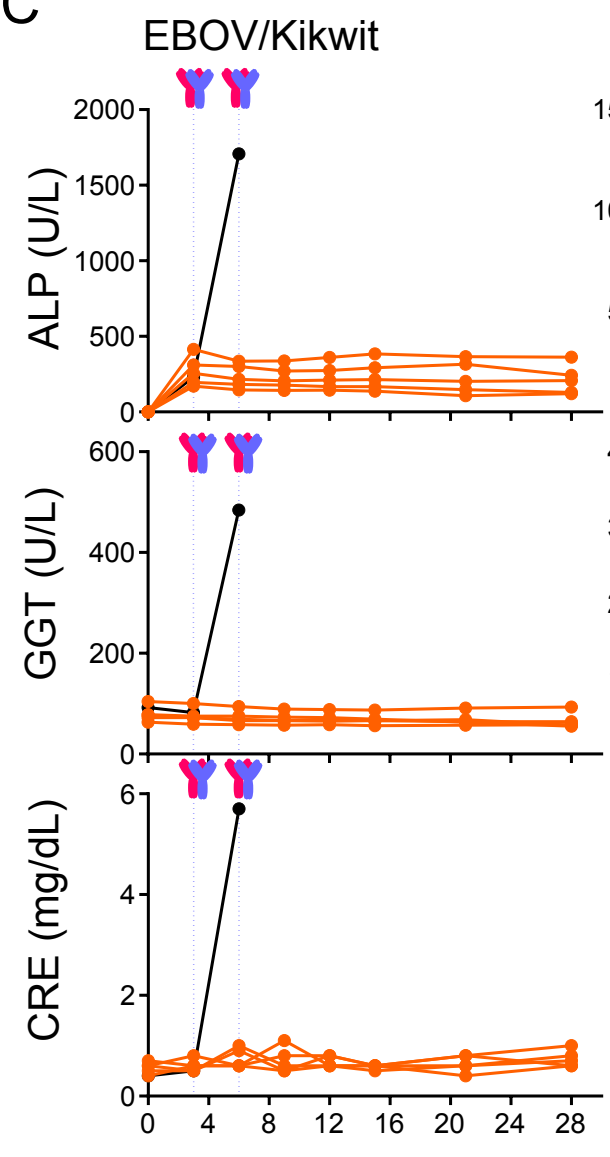

BDBV/Uganda

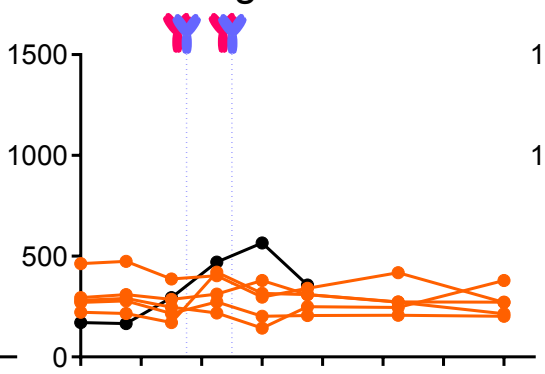

Figure 4

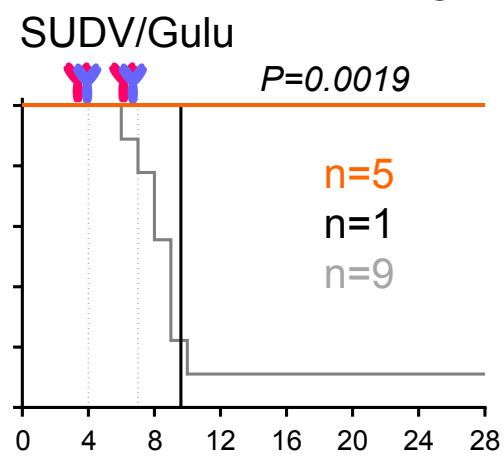

\section{SUDV/Gulu}
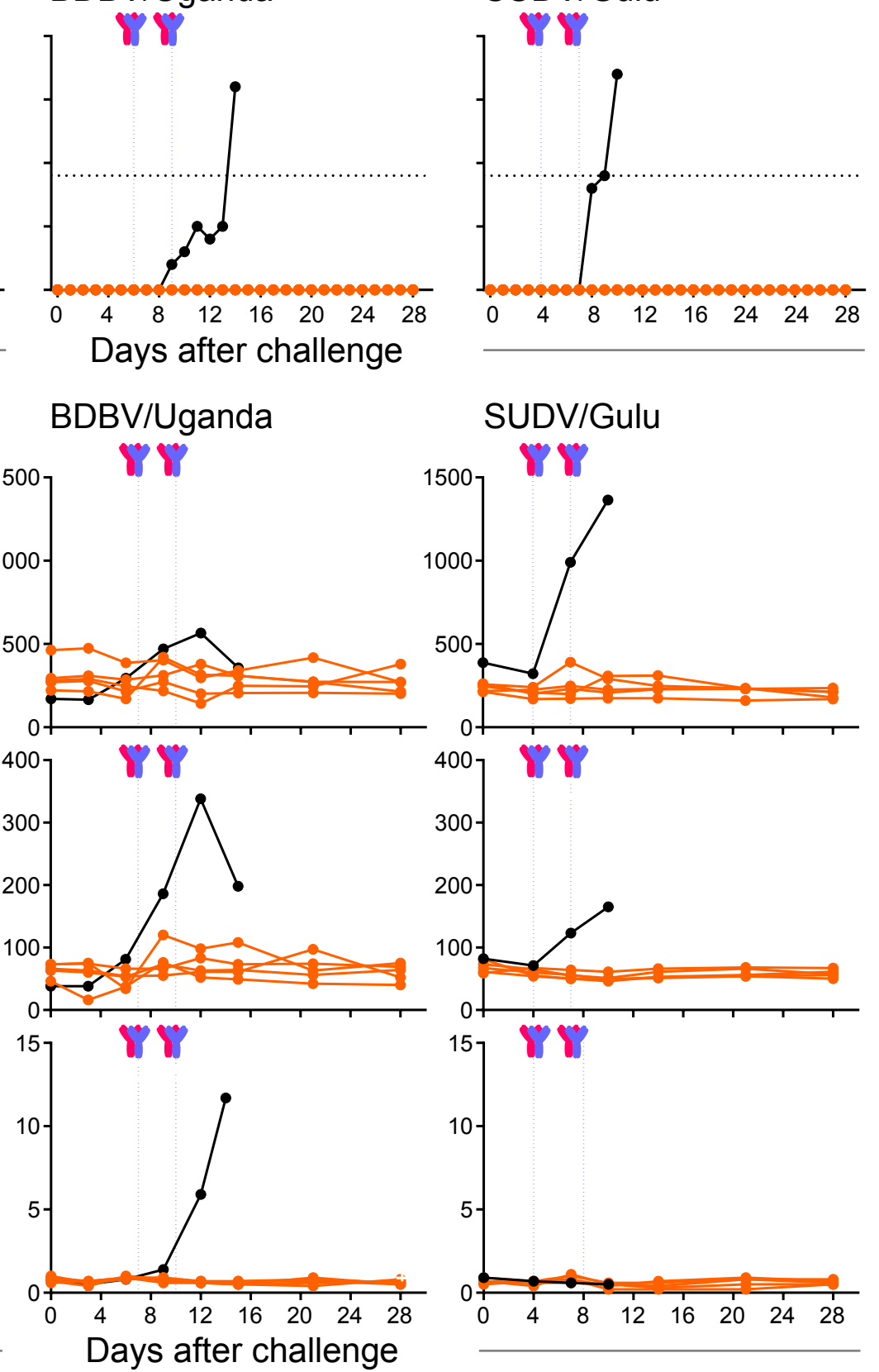

SUDV/Gulu

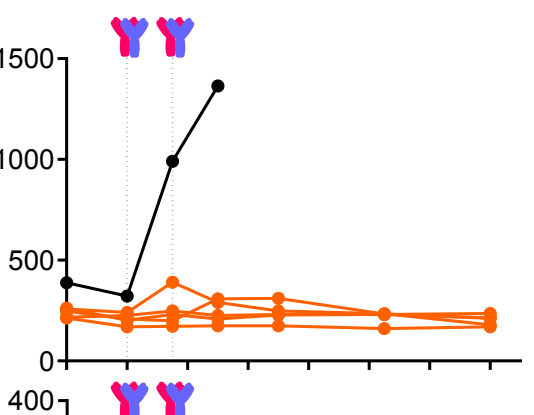

$300-$

200
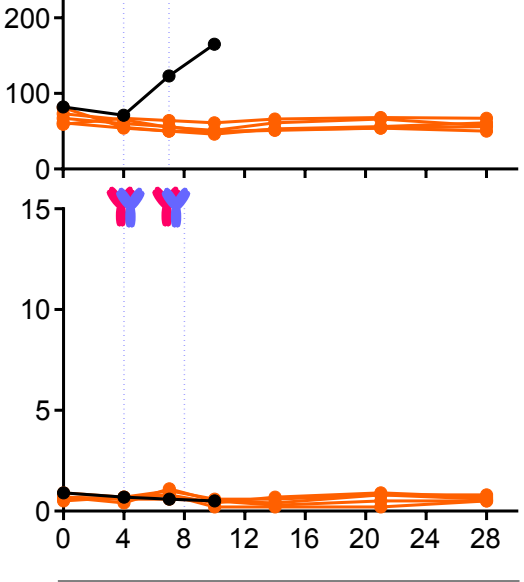
A
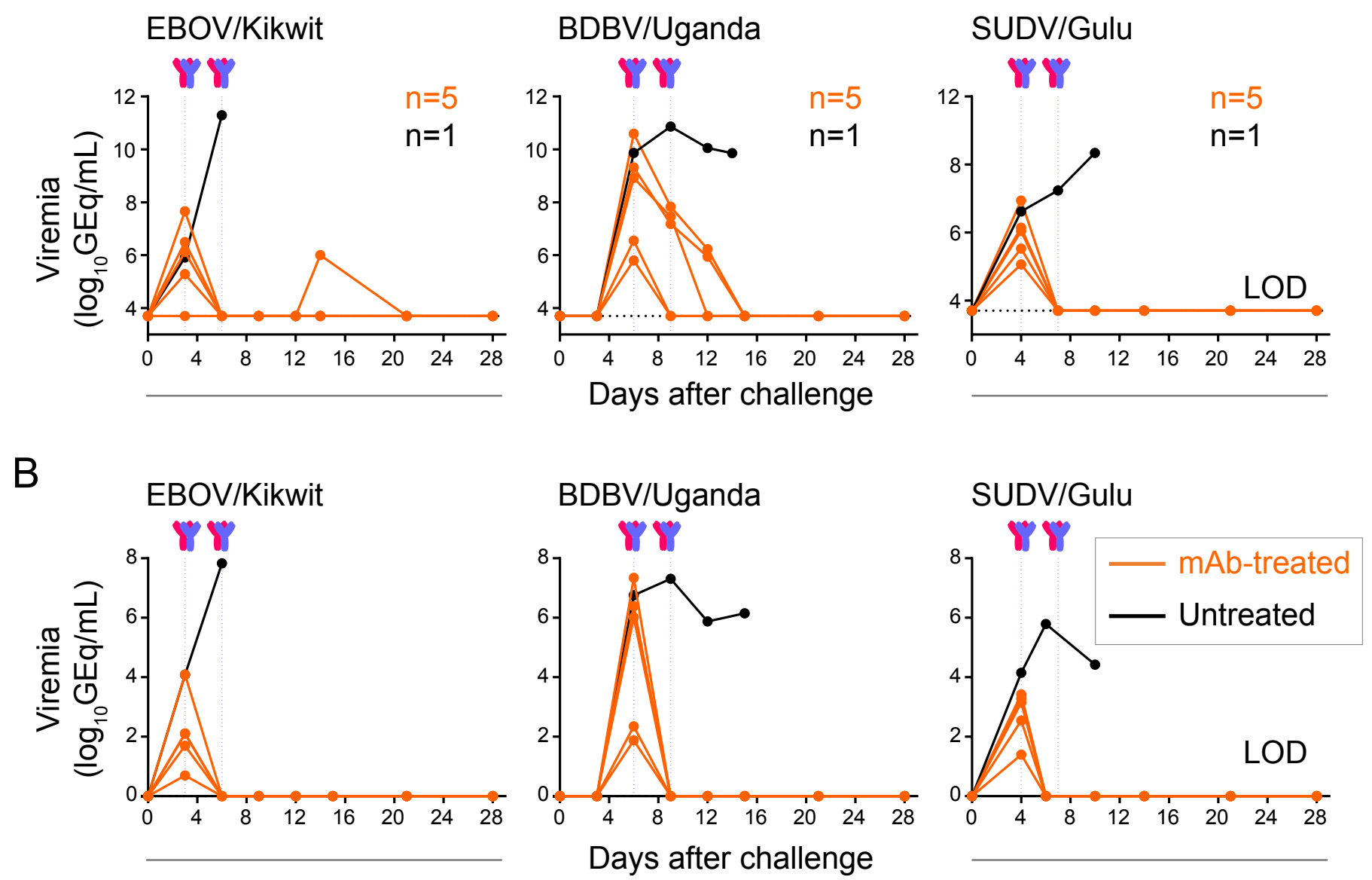
B
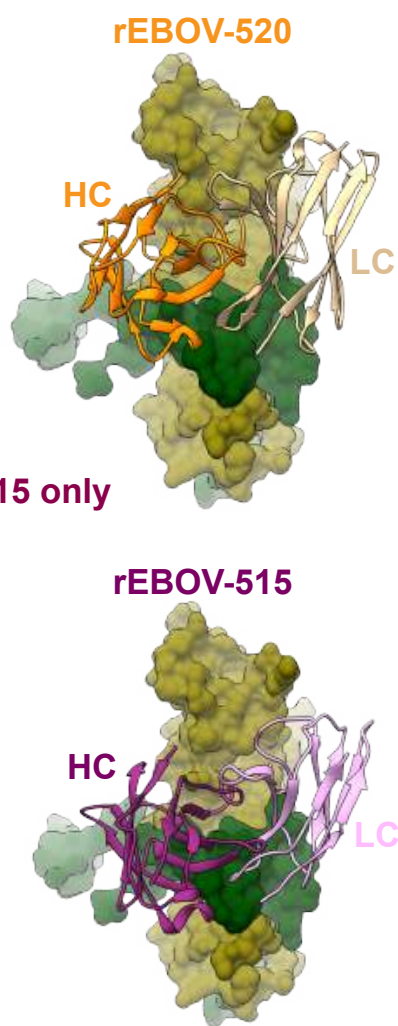
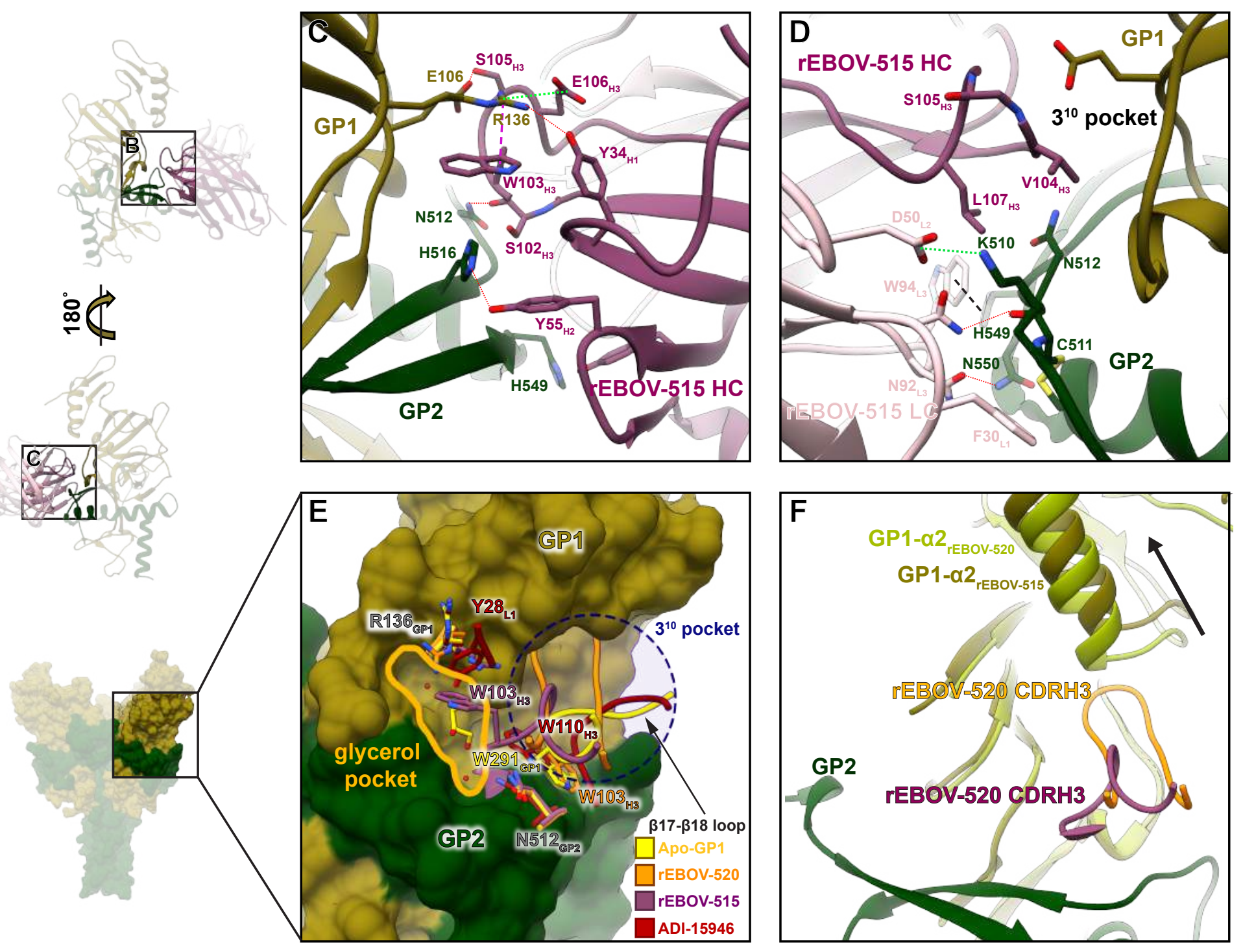

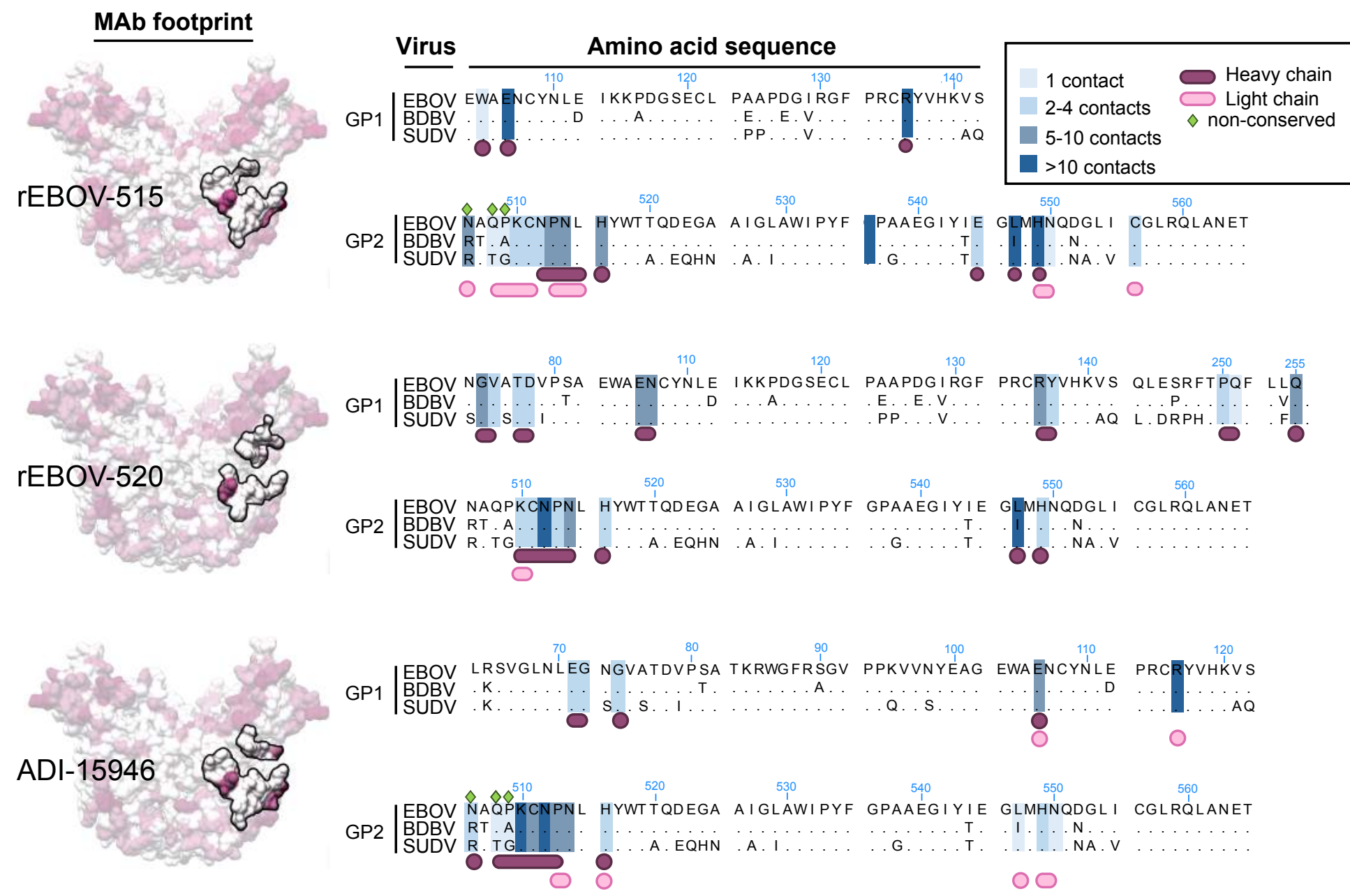

Amino acid conservation

$100 \%$ $0 \%$ 